CuPAUAM. 18-1991, 113-148

\title{
NUEVOS ELEMENTOS DE CARROS ORIENTALIZANTES EN LA ALTA ANDALUCIA. ALGUNAS PRECISIONES EN TORNO A SU FUNCION, SIGNIFICADO Y DISTRIBUCION
}

\author{
FerRer ALBELDA, E. \\ Mancebo Davalos, ]. \\ UNIVERSIDAD DE SEVTLIA
}

\section{Resumen:}

El objetivo de estas líneas es la presentación de dos conjuntos de piezas de cartos de Cástulo y Ubeda La Vieja, de cuyo análisis estilístico y comparativo con otros ejemplates peninsulares deducimos su filiación orientalizante.

A la vez, pretendemos hacer una tipología provisional de las piezas existentes y distinguir los carros de este período de los ibericos por su morfología y distribución.

Por último, hacemos unas reflexiones sobre las sociedades que utilizan estos carros, y exponer la relación de éstos con las estelas decoradas del Sudoeste.

\section{Summary:}

The objetive of these lines is the presentation of two groupe of pieces belonging to carts from "Cástulo y Ubeda la Vieja". Their stylistic and compatative analysis with other peninsular items makes us deduce their "Orientalizante" source.

At the same time, our intention is to make a provisional typology of the existing pieces, and stablish the difference between the carts belonging to his period and the Iberian ones, according to their morphology and distribution.

Finally, we present some notes about the societies that use carts and the relationship between these and the decorated wakes from the southwest.

\section{INTRODUCCION.}

El estudio de los carros peninsulares y de sus distintos componentes han sido objeto de reflexión por los investigadores españoles desde fines del siglo pasado, tendiendo principalmente a desglosar este estudio en tres focos de atención: los hallazgos de fragmentos de ruedas o las diversas 
piezas de los carros aparecidos en excavaciones o museos, las representaciones votivas de estos carros, y los interpretados como tales en las estelas decoradas del Suroeste.

Fue sin duda el hallazgo de Solana de Cabañas por Mariano Roso de Luna (1898) el que marcó la pauta de estudio de estos elementos en este tipo de representación.

Al interés presentado por el descubrimiento de nuevos ejemplares sobre estelas a principios de siglo, estidiadas por Breuil entre otros (1916), hay que sumar también los hallazgos de piezas auténticas de carros en excavaciones como las de Toya o Galera por Cabré (1924; ibid. 1925; y Motos, 1920), que suponen una constatación real de lo que hasta el momento sólo se había podido apreciar esquemáticamente en algunas estelas decoradas.

Será a partir de estos años cuando encontremos una serie de publicaciones que abarcan el estudio de estos elementos según su representación:

- En cuanto a la representación del carro como exvoto o carro votivo, hay que contar con los primeros trabajos de Sandars (1906) sobre las piezas ofrendadas en los santuarios giennenses de la zona de Despeñapertos. No olvidemos que ejemplares de la colección Sandars-Vives, pertenecientes a estos santuarios, han aparecido diseminados por varios museos españoles, y fueron objeto de análisis y catalogación por otros investigadores como Alvarez Osorio, con las piezas depositadas en el M.A.N. (1935), o los trabajos de Serra Rafols sobre el carro votivo del Museo de Granollers, proveniente sin duda de Despeńaperros o del Castellar de Santisteban (1948, 379).

Junto a estos objetos, fueron apareciendo otros en zonas relacionadas con lo que se ha venido denominando "el impacto Orientalizante", como el carrito votivo de Bencarrón (Los Alcores, Sevilla), estudiado por Bonsor, y que se distingue por estar modelado en arcilla y no en bronce como los demás $(1924,175)$; o los carros votivos del área extremeña, analizados repetidamente por autores como Forrer (1932), Blázquez (1955; ibid., 1975; ibid., 1976), y Almagro-Gorbea (1977; ibíd., 1985). Se trata de los carros de Mérida y el de Almorchón.

- Por orro lado, tenemos las referencias de estos elementos sobre las estelas llamadas "decoradas del Suroeste".

Como ya hemos visto, los primeros avances se los debemos a autores como Roso de Luna, Breuil - Cabré, pero será preciso esperar a los años cincuenta para contar con investigaciones más profundas sobre el tema como las de Fernández Oxea (1950), estudios que sirvieron de base para que M. Almagro Basch realizara en 1966 el primer corpus sobre estas estelas, recogiendo toda la documentación conocida hasta la publicación de su libro, donde las representaciones con carros son incluidas en su tipo II, fechado de forma global del 800 a.C. en adelante $(1966,208)$, y más concretamente, las estelas con carros de este grupo, se fechan a partir del 700 a.C. (estela de Torrejón El Rubio I como la estela más antigua de este tipo) por la asociación de otros elementos también representados en ellas (1966, 195-96). Interesa también destacar el dato ofrecido en su valoración sobre los carros votivos, citando entre sus paralelos el nuevo ejemplar de Costa Figueira en Portugal, aparte de los ya mencionados de la zona giennense $(1966,195)$.

A este esfuerzo tipológico realizado por M. Almagro, le siguen estudios como los de Pingel (1974), y una serie de trabajos aparecidos en el mismo año, como los de M. Almagro-Gorbea en su obra sobre el Bronce Final y el Período Orientalizante de la zona exuremeña $(1977,185)$, Varela y Pinho, en su versión portuguesa y española (1977), y el de M. Bendala, quien nos recuerda en su análisis, como ya hiciera a su vez Almagro-Gorbea, que son dos las ruedas reflejadas en estas representaciones, y no cuatro como había pensado $M$. Almagro al identificar como ruedas posteriores los asideros de estos carros. $(1977,183)$. 
Desde entonces, son muchas las estelas que han ido apareciendo y suscitando una bibliografia tan abundante como diversa sobre temas aún no muy claros de su origen y cronología. Son las obras de M. Bendala (y otros, 1979-80) sobre estelas con representaciones de carros cordobesas; Bueno y Piñón (1985, 37-44) y S. Celestino (1985; ibid., 1990; Celestino y otros, 1989), con estudios referidos a los nuevos hallazgos de la zona excremeña; los trabajos de A. Muzzolini, quien intenta esclarecer el tema del origen de los carros tepresencados en las losas ibéricas y marroquíes (1987); o los novedosos estudios de Barceló, aplicando las avanzadas técnicas informáticas a su investigación, y extrayendo conclusiones que chocan con las tesis tradicionales, al considerar a estos objetos representados en las estelas (los carros entre ellos) como anteriores a la llegada de los semitas a la Península, y otorgándoles por tanco una cronología entre los siglos XI (relaciones atlánticas) y VIII a.C. para su final (1989).

Se enfrenta de este modo a las últimas investigaciones de autores como $\mathrm{M}$. Pellicer, quien las sitúa desde el siglo IX al VI a.C., atendiendo a paralelos tanto atlánticos como mediterráneos (1989, 173), o los últimos trabajos de Blázquuez, quien los relaciona directamente con el influjo de las actividades fenicias por el Mediterráneo (1986 b, 194).

- En cuanto al tercer elemento, no vamos a contabilizar los numerosos estudios que han ido apareciendo a partir de los continuos hallazgos que se han dado en las excavaciones realizadas desde aquellas primeras de Cabré en Toya o Galera (1925; y Motos, 1920), pero si queremos destacar la importancia que ha representado para el mejor conocimiento de estos datos el tesón de algunos investigadores como E. Cuadrado, quien, desde 1949, en su trabajo sobre los arreos de montar ibéricos, no ha dejado de investigar acerca de lo que el caballo y el carro ha representado para la cultura ibérica en la zona de Murcia a raíz de sus excavaciones en El Cigaralejo (1950; ibíd., 1984; ibíd., 1987), dando a conocer otros ejemplares como los restos aparecidos en El Macalón.

También hay que destacar los trabajos de Arribas en el Mirador de Rolando, quien cita como uno de sus paralelos los hallazgos de Villaricos, que habían quedado olvidados en las investigaciones precedentes (Arribas, 1967, 193), aunque si consultamos la publicación de L. Siret $(1906,78$ y 84), podremos ver ciertas piezas relacionadas con posibles carros y arneses de animales.

Otras excavaciones posteriores como las efectuadas por J.P. Garrido en la necrópolis de La Joya, dieron a conocer elementos suficientes como para reconstruir gran parte de la estructura de estos carros utilizados en el mundo funerario, gracias a los descubrimientos de las tumbas 17 y 18 . Son carros de dos ruedas (según el número de cubos encontrados) y doble ciro con paralelos chipriotas (Garrido y Orta, 1978).

Otros estudios dedicados a este tema, se los debemos a autores como M. Almagro Basch, sobre la toreútica orientalizante, que documentar fragmentos tan representativos como los de Maquiz, en Jaén, ampliando el número de piezas presentadas en su dia por Amador de los Ríos (Almagro, 1979, 173); los restos de herrajes de carro y bocados de caballo de la necrópolis de Baza (Presedo, $1982,37,237$ y 264); o los espectaculares resultados de las excavaciones del palacio-santuario de Cancho Roano, donde han aparecido ricos elementos de atalajes de caballos y piezas metálicas pertenecientes a carros (Maluquer, 1981; ibíd. 1983; Maluquer y otros, 1986).

Como hemos podido apreciar, eran muchos y muy dispersos los datos con los que se encontraba el estudioso del tema hasta hace unos años. Sin embargo, la excelente obra de FernándezMiranda y Olmos (1986) sobre las ruedas de Toya, ha supuesto un gran esfuerzo de recopilación y síntesis con todos los documentos disponibles hasta su realización.

Con rodo, las nuevas actividades arqueológicas se prestan a ir sumando más datos que dejan incompleto cualquier intento de corpus sobre el tema, como la apatición de una ruedecita de bronce del mismo tipo que las halladas en Cancho Roano, en el yacimiento onubense de Tejada La 


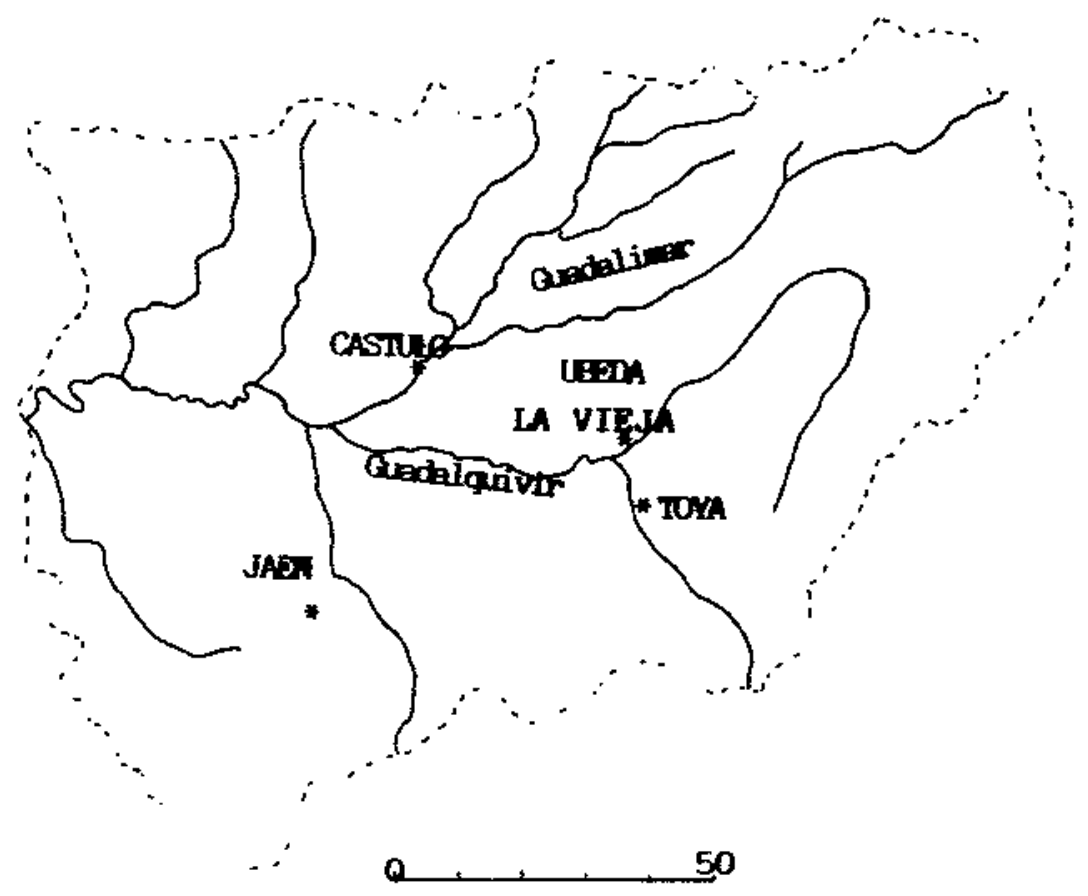

Figura No 1,- Localización de yacimientos.

Vieja (Fernández Jurado, 1987, Lám. LIII); o el interesante tramo del camino pretromano con huellas de ruedas de carros descubierto en Castellar de Meca (Broncano y Alfaro, 1990).

De esta forma, las nuevas excavaciones y en otros casos hallazgos casuales hacen surgir en colecciones particulares nuevos elementos como las piezas correspondientes al enjaezamiento de caballos y carros de la Fundación Alhonoz (l), que proceden de la zona giennense, tan pródiga en estos materiales (Fig. 1). Queremos con su estudio, avanzar un poco más sobre la importancia que estos elementos guardan en los períodos Orientalizante e Ibérico en la Península.

\section{CATALOGO DE PIEZAS.}

\section{Conjunto A.}

- Depósito: Fundación Alhonoz.

- Procedencia: Ubeda, Jaén.

(1) Desde estas lineas, quezemos expresar nuestro agradecimiento a las personas encargadas de dicha Fundación, que ban pueszo amablemente a nuestra disposición zodos los datos e instrumentos necesarios paza el presente eseudio. 
- Circunstancia del hallazgo: Fortuito, sin contexto.

- Estado de conservación: Excelente. Ha sido restaurado recientemente, eliminando los focos de óxido y las concreciones que tenian las piezas (2).

- Metal: Todas las piezas son de bronce.

- Relación de piezas:

\section{PIEZA A.1 (Fig. 2, 1)}

Descripción Pasarriendas de bronce en el que se pueden distinguir tres partes diferenciadas: la cabeza, circular, formada por un aro de sección redondeada separada en dos por un filete aplastado cuya función sería la de enganchar las riendas; la corona o cresta que se sitúa en la superficie exterior del aro a partir de la mitad superior de éste. La forman quince pequenas piezas romboidales unidas entre sí en su parte inferior, con apariencia dentada, y que no son sino la estilización de motivos vegetales (Fernández- Miranda y Olmos, 1986, 94), posiblemente capullos de flor de loto. Esta parte es puramente ornamental, sin otra función que la de adornar, como lo prueban otras piezas (algunas de este catálogo) que están desprovistas de ella (Maluquer, 1981, 408, Lám. XL; MartínezBotella, 1980, 302). Por último la parte inferior o vástago, aplastada y más ancha en su unión con la cabeza que en extremo inferior. Es de sección rectangular y pieza de unión con la caja del carro.

\section{Dimensiones.}

- longitud máxima: $116 \mathrm{~mm}$.

- anchura máxima: $85 \mathrm{~mm}$.

- longitud del vástago: $48 \mathrm{~mm}$.

- diámetro de la cabeza: $51 \mathrm{~mm}$.

- grosor del aro: $9 \mathrm{~mm}$.

Peso: 176 gr.

PIEZA A.2. (Fig. 2, 2)

Descripción: Pasarriendas de bronce muy parecido al anterior pero de proporciones más chatas. La corona se compone en esta ocasión de diecisiete capullos, y el vástago, también de sección rectangular, no tiene el estrechamiento inferior de la pieza A.1.

\section{Dimensiones:}

- longitud máxima: $104 \mathrm{~mm}$

- anchura máxima: $85 \mathrm{~mm}$.

- longitud del vástago: $37 \mathrm{~mm}$.

- diámetro de la cabeza: $52 \mathrm{~mm}$.

- grosor del aro: $11 \mathrm{~mm}$.

Peso; $207 \mathrm{gr}$.

(2) Agradecemos el inzeres y disposición del equigo de resrauración de la Fundación Alhonoz, gaienes nos enviaron desde Madrid los nuevos resuleados obtenidos tras las labores de limpieza y restauración de escas piezas. 

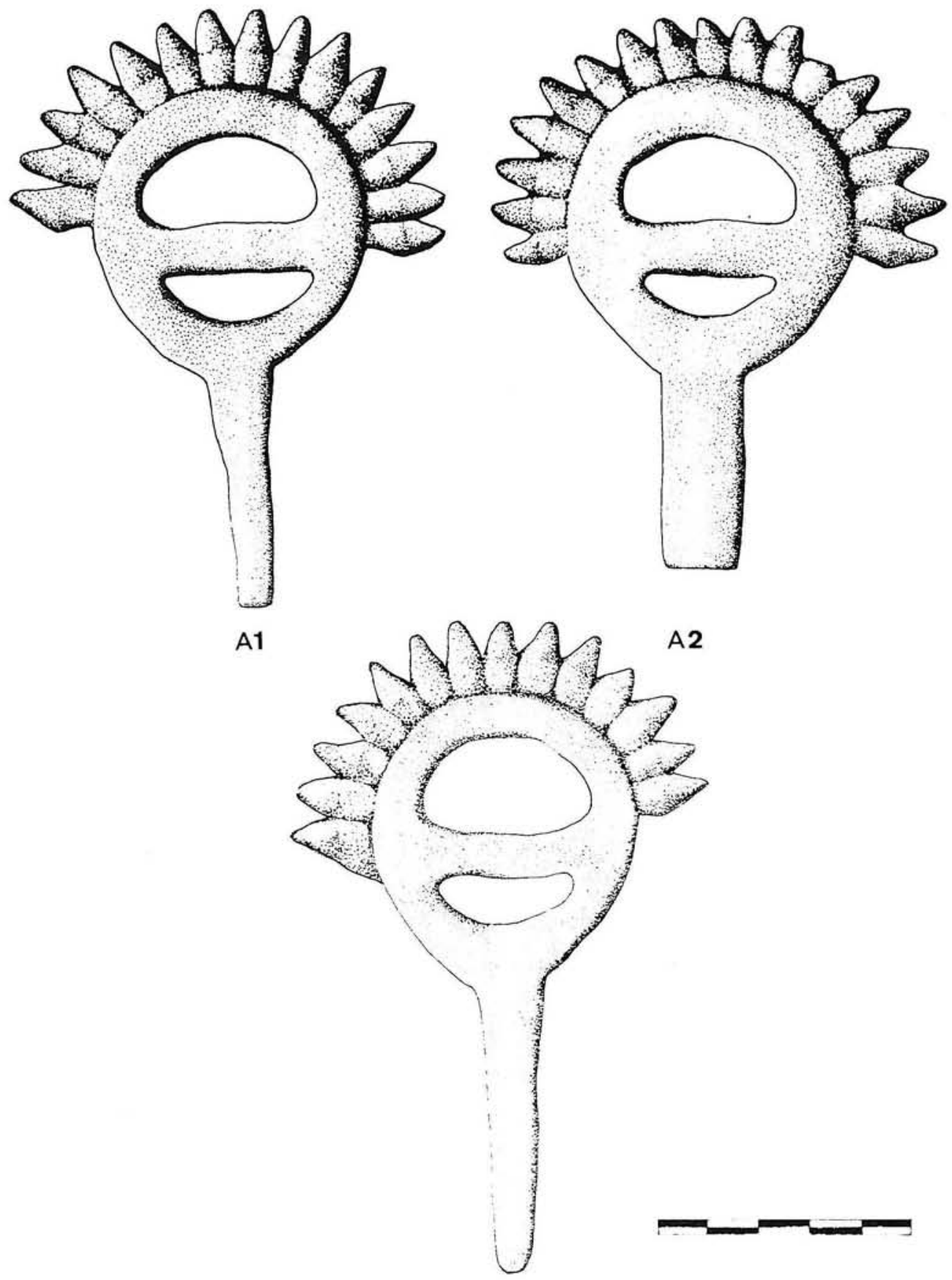

A3

Figura № 2.- Ubeda la Vieja. 
PIEZA A.3. (Fig. 2, 3)

Descripción: Similar a las anteriores pero con catorce capullos de loto en la corona y el vástago con estrechamiento.

\section{Dimensiones:}

- longitud máxima: $122 \mathrm{~mm}$.

- anchura máxima: $83 \mathrm{~mm}$.

- longitud del vástago: $52 \mathrm{~mm}$.

- diámetro de la cabeza: $52 \mathrm{~mm}$.

- grosor del aro: $11 \mathrm{~mm}$.

Peso: $173 \mathrm{gr}$.

PIEZA A.4. (Fig. 3, 1)

Descripcion: Filere articulado de bocado de caballo compuesto por dos piezas trenzadas engarzadas entre sí mediante dos argollas grandes, y terminado en dos argoilas menores. Esta pieza se situaba dentro de la boca del caballo e iba unida a placas laterales móviles (camas) con distintos remaches. Por encima de éstas se situaba el tirante ( a veces en forma de $T$ ) cuya función era sujetar el freno a la cabeza de los animales (Garrido, 1978, 87; Fernández-Miranda y Olmos, 1986, 93).

Dimensiones: las dos piezas que componen el filete son idénticas.

- longitud máxima: $199 \mathrm{~mm}$.

- diámetro de la argolla mayor: $28 \mathrm{~mm}$.

- diámetro de la argolla menor: $17 \mathrm{~mm}$.

- grosor del cafion: $11 \mathrm{~mm}$.

Peso: 66, $650 \mathrm{gr}$.

PIEZA A.5. (Fig. 3, 2)

Descripción: De iguales características que la pieza A.4.

Dimensiones:

- longitud máxima: $198 \mathrm{~mm}$.

- diámetro de la argolla mayor: $29 \mathrm{~mm}$.

- diámetro de la argolla menor: $17 \mathrm{~mm}$.

- grosor del canón: $11 \mathrm{~mm}$.

Peso: 66, $60 \mathrm{gt}$. 


\section{PIEZAS A.6.-A.10. (Fig. 4)}

Descripción: Botones cónicos de bronce, en total cinco, muy semejantes entre sf pero ninguno exactamente igual a los otros, hecho que se aprecia mas fácilmente en su sección. Son piezas macizas compuestas por una placa con el borde recortado, formando un dentado, y con varios cuerpos que acaban en punta, y un travesaño en el reverso, fundido en la misma pieza, que sobresale poco de ésta. El espacio necesario para introducir el sedal o la tira de cuero se ha hecho a expensas de la placa, rebajándola un poco, lo que ha dado lugar a un pocillo.

Su función es, en el estado actual de nuestros conocimientos, puramente ornamental. Siempre van unidos a los atalajes de caballos (Maluquer, 1981, 331) por lo que debieron ir prendidos de las camas o de las piezas frontales.

Dimensiones:

$\begin{array}{llllll}\text { Piezas } & \text { A.6. } & \text { A.7. } & \text { A.8. } & \text { A.9. } & \text { A.10. } \\ \text { diámetro: } & 42 & 39 & 39 & 44 & 41 \mathrm{~mm} \text {. } \\ \text { longitud sección: } & 22 & 24 & 19 & 20 & 25 \mathrm{~mm} \text {. } \\ \text { Peso. } & 68,20 & 53,15 & 42,90 & 47,63 & 62,30 \mathrm{gr}\end{array}$

PIEZAA. A.11. (Fig. 5, 1)

Descripción. Desconocemos por ahora el nombre y la función de este tipo de piezas, pero su pertenencia al conjunto A. y su similizud a otros elementos de carros, aunque con distinta función (Garrido, 1978, 76, fig. 46), la hacen con seguridad parte integrante del atalaje de un caballo o del carro. Está formado por una placa circular con orificio redondo central y bordes regruesados con dos argollas juntas unidas a la placa.

\section{Dimensiones:}

- diámetro de la placa: $68 \mathrm{~mm}$.

- diámetro orificio central: $23 \mathrm{~mm}$.

- grosor máximo: $6 \mathrm{~mm}$.

Peso: 158 gr.

\section{PIEZA A.12 (Fig. 5, 2)}

Descripción Iguales características que la pieza anterior con la diferencia que aquella está en un estado de conservación casi perfecto y la pieza A.12. aparece completamente doblada y con la placa corroída en parte.

\section{Dimensiones:}

- diámetro placa: $62 \mathrm{~mm}$.

- diámetro orificio central: $22 \mathrm{~mm}$.

- grosor máximo: $5 \mathrm{~mm}$.

Peso: $159 \mathrm{gr}$. 

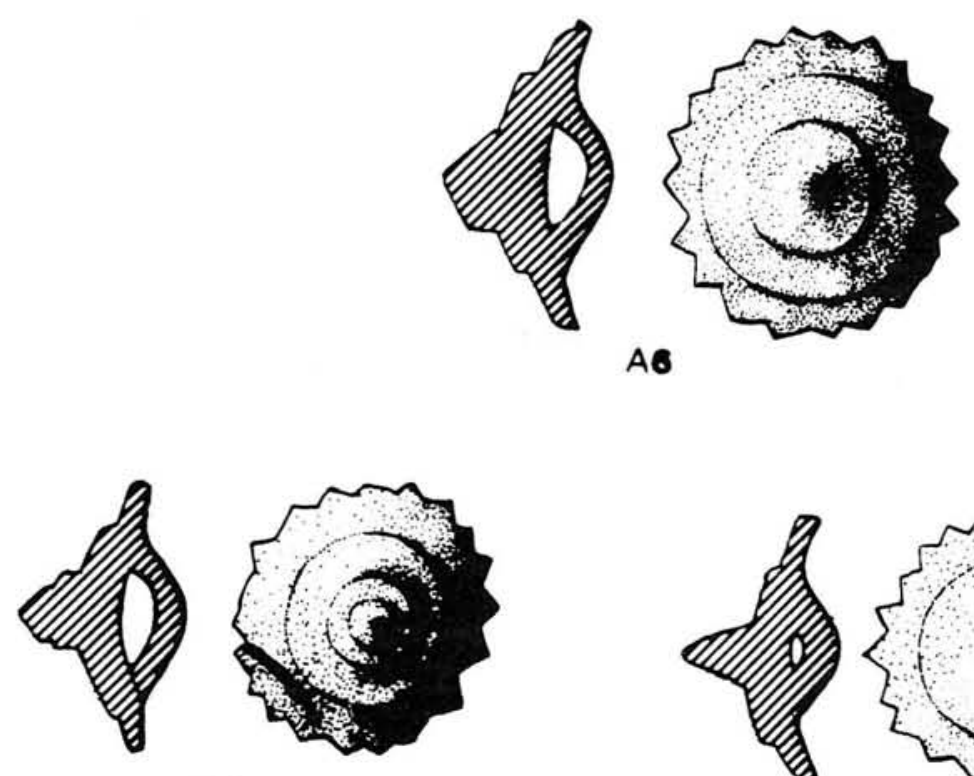

A7
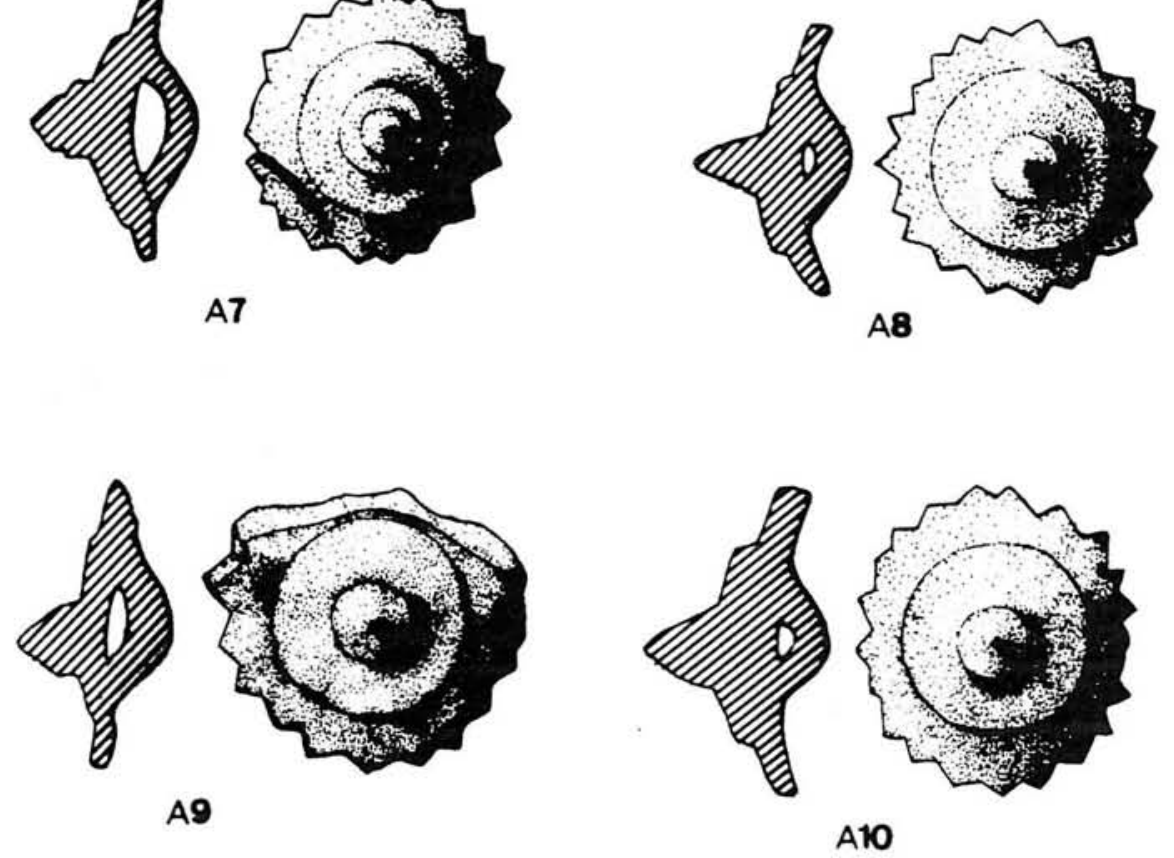

Figura No 4.- Ubeda la Vieja. 

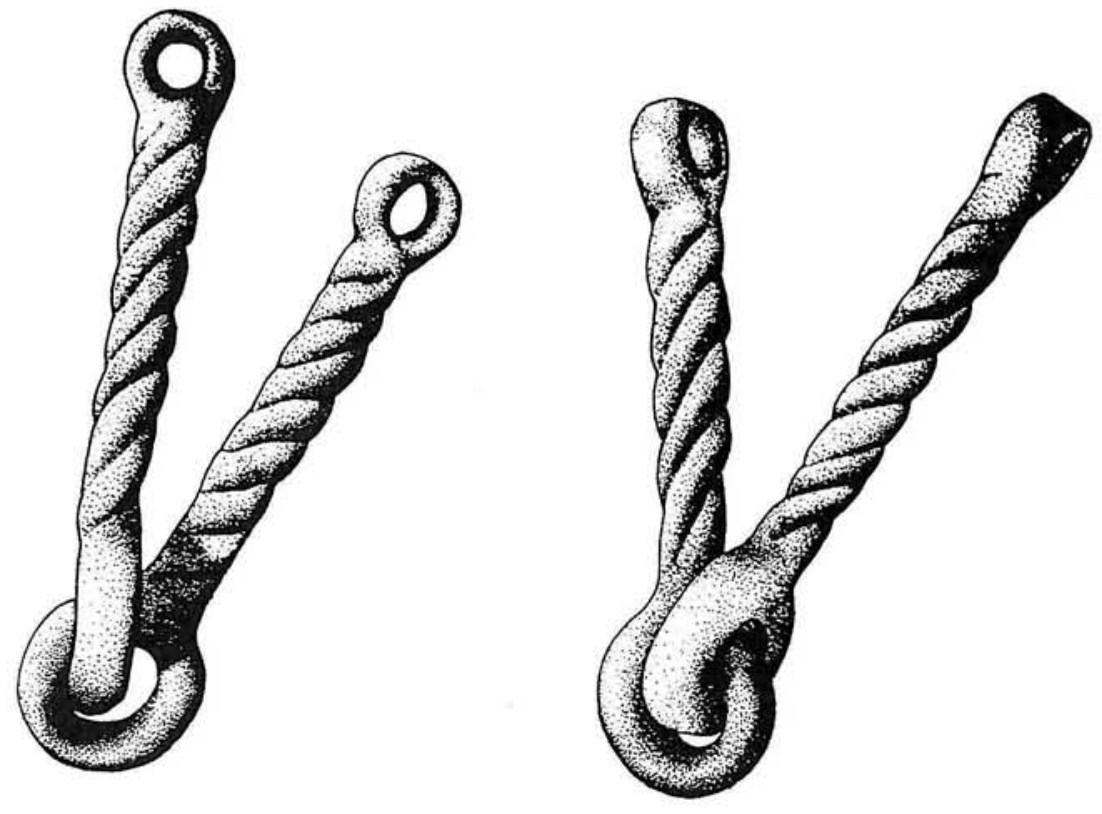

A4

A5
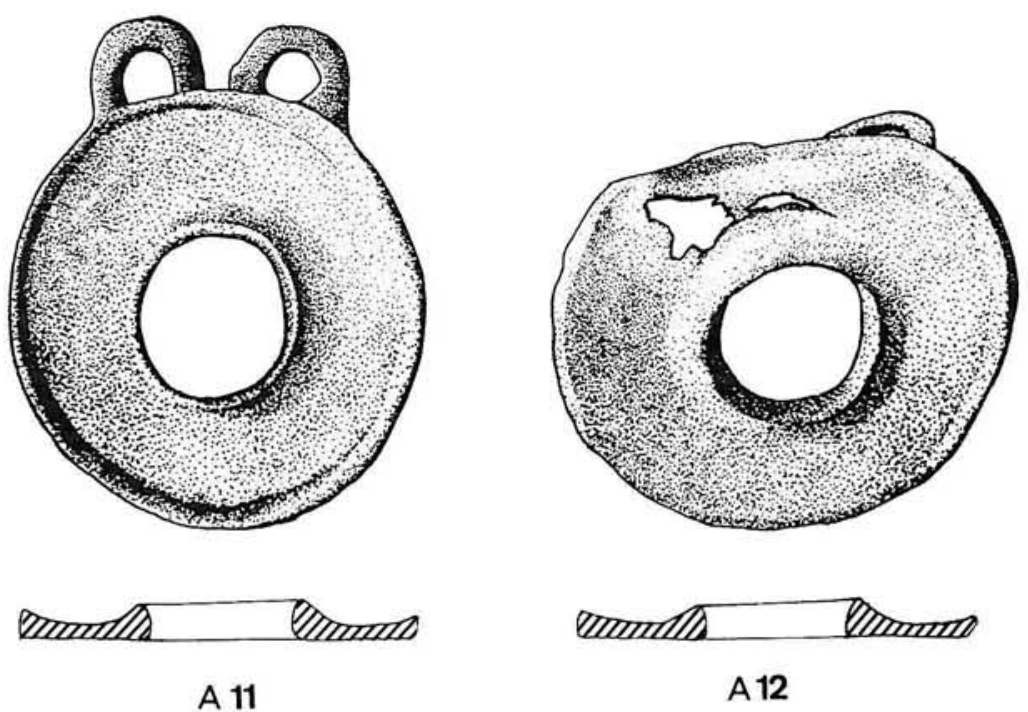

Figs. 3 y 5 .- Ubeda la Vieja. 


\section{CONJUNTO B.}

- Depósito: Fundación Alhonoz.

- Procedencia: Cástulo. Jaén.

- Circuntancia del hallazgo: Fortuito. Sin contexto.

- Estado de conservación: Bueno. Presenta algunos focos de oxidación.

- Metal: Todas las piezas son de bronce.

- Relación de piezas:

PIEZA B.1. (Fig, 6, 1)

Descripción: Pasarriendas simple, con la cabeza formada por un aro de sección circular y filete delgado, con huellas de uso, y un vástago corto, de sección rectangular.

\section{Dimensiones:}

- longitud máxima: $127 \mathrm{~mm}$.

- diámetro cabeza: $87 \mathrm{~mm}$.

- longitud vástago: $42 \mathrm{~mm}$.

- grosor del aro: $10 \mathrm{~mm}$.

Peso: $198,63 \mathrm{gr}$.

PIEZA 8.2. (Fig. 6, 2)

Descripción: Semejante a la anterior pero de menor tamafio.

\section{Dimensiones:}

- longirud máximo: $101 \mathrm{~mm}$.

- diámetro cabeza: $65 \mathrm{~mm}$.

- longitud del vástago: $46 \mathrm{~mm}$.

- grosor del aro: $8 \mathrm{~mm}$.

Peso: 110,57 gr.

\section{PIEZA B.3. (Fig. 6, 3)}

Descripción Idéntica a la pieza B.2., pero le falta el vástago por rotura.

\section{Dimensiones:}

- diámetro de la cabeza: $64 \mathrm{~mm}$.

- grosor del aro: $8 \mathrm{~mm}$.

Peso: $78,33 \mathrm{gr}$. 


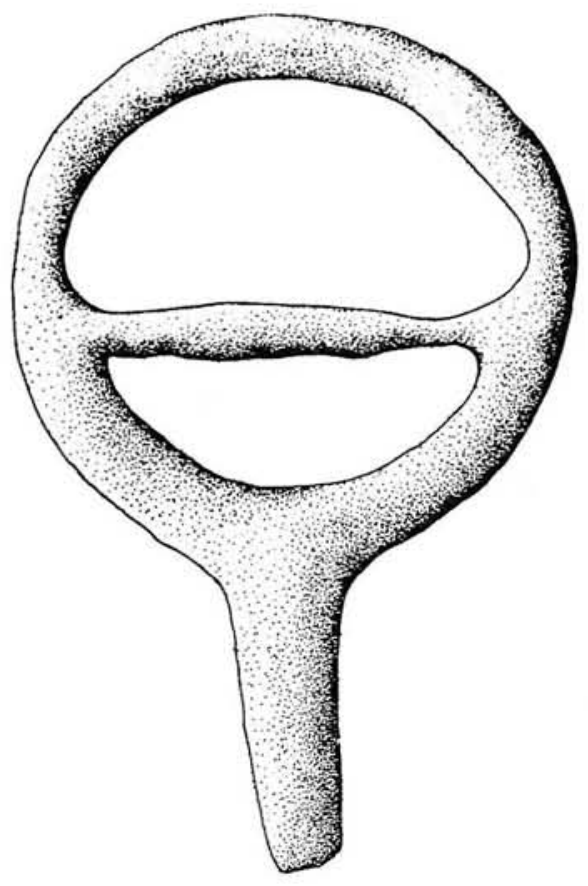

B1
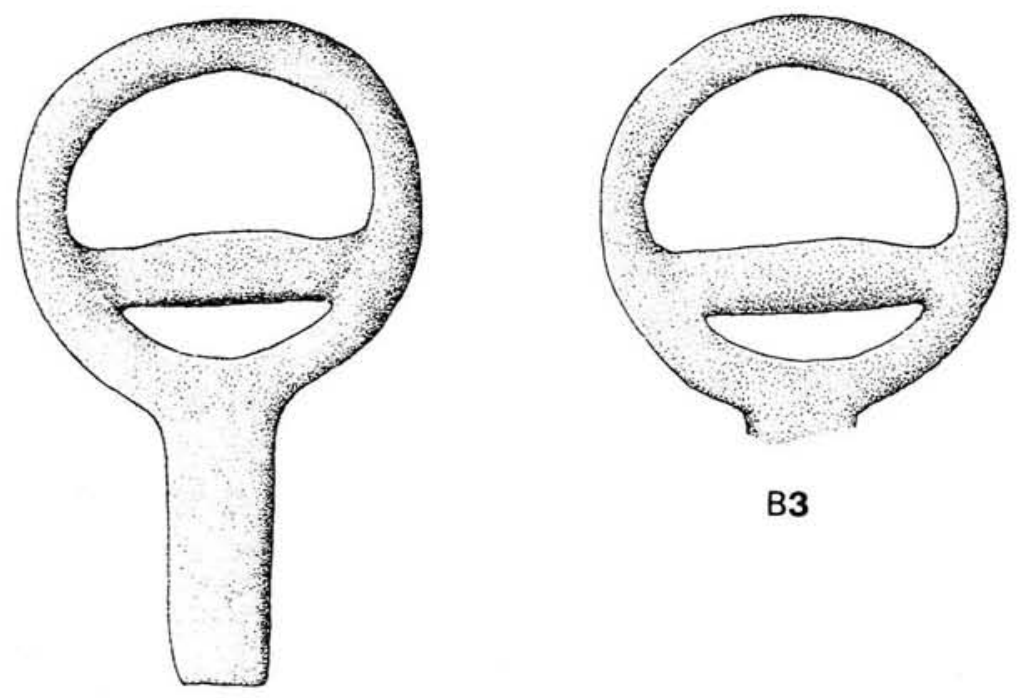

B3

B2

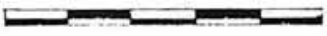

Figura No 6.- Cástulo. 


\section{PARALELOS DE LAS PIEZAS}

A la hora de establecer los distintos paralelos de las piezas descritas en el catálogo, hemos querido establecer dos grupos de materiales, destacando por un lado, las piezas telacionadas directamente con los carros, como son los pasarriendas, y por otro, las relacionadas con los animales de tiro, los bocados y botones de bronce, que decoran los cabezales de los cabalios.

\section{PASARRIENDAS:}

A) DECORADOS: Son varios los estudios que se han realizado sobre piezas similares a las aparecidas en Ubeda. Dentro del mismo grupo, por su estilo decorativo a base de motivos vegetales, citamos el ejemplar de Alcacer Do Sal (Fig.7, 1), dado a conocer por Schüle (1969, Lám. 108, 8), como procedente de ésta necrópolis y que se encuentra actualmente en el museo de Belem. Muestra, como las restantes piezas de este tipo, huellas claras de su uso en el desgaste del vástago central, producido por el roce de las riendas de cuero, y presenta, a diferencia de la recogida en Ubeda, motivos calados que individualizan los capullos de flor de loto. Es muy semejante a la pieza recogida por M. Almagro $(1979,187)$ de procedencia desconocida y expuesta actualmente en el Museo Arqueológico de Barcelona (Fig.7, 2), pero se diferencia de la anterior en el menor número de elementos decorativos, (quince en lugar de los diecisiete que presenta la pieza portuguesa) y por un mayor desgaste en la zona de contacto con las bridas.

Una tercera pieza, que basa su decoración en la alternancia de palmetas de claro gusto oriental con las estilizaciones de capullos de loto, perteneció a la Colección Vives (Fig. 8), y fue publicada por Garcfa y Bellido (1970, 38-39) como hebilla de cinturón, aunque en las revisiones postetiores (Almagro, 1979, 187; Fernández Miranda-Olmos, 1986, 94) aparece ya como pieza indiscutible de un carro orientalizante. Todos aceptan la cronología propuesta por Culican, $(1971,156-58)$ entre el 700 y el 600 a.C. $(1971,156-58)$, fecha que sirve de referencia para datar las piezas anteriores.

B) SIN DECORACION: Al analizar las piezas procedente de Cástulo, y buscar sus paralelos exactos, hemos comprobado al menos la existencia de tres subtipos distintos de pasarriendas sin decoración vegetal:

- En el PRIMER SUBTIPO, hay que situar además de las piezas citadas como B.1., B.2. y B.3., de nuestro catálogo, la recogida por Maluquer $(1981,408$ y Lám. XI, b)fuera del rúmulo de Cancho Roano, perteneciente a las tierras extraídas de la parte meridional, es decir, fuera de contexto estratigráfico fiable. No se trata de una pieza de bocado de caballo como piensa el autor, sino de un auténtico pasarriendas como los mencionados en el apartado anterior, sin el remate floral. Creemos que su cronología no es tan baja como piensan los autores (Fernández Miranda-Olmos, 1986, 94), y que debe situarse en relación a esos otros materiales, también aparecidos fuera del edificio, como un arybalos naukrátida del siglo VI a.C. (Maluquer 1981, 277), que nos hablan de un momento de esplendor de éste palacio en una fase plenamente orientalizante, como dejan entrever las últimas excavaciones (Almagro- Gorbea, 1990, 101).

Junto a esta pieza, destacamos la existencia de otra exactamente igual a las mencionadas, también con huellas evidentes del desgaste producido por el uso, y bien documentada estratigráfica- 


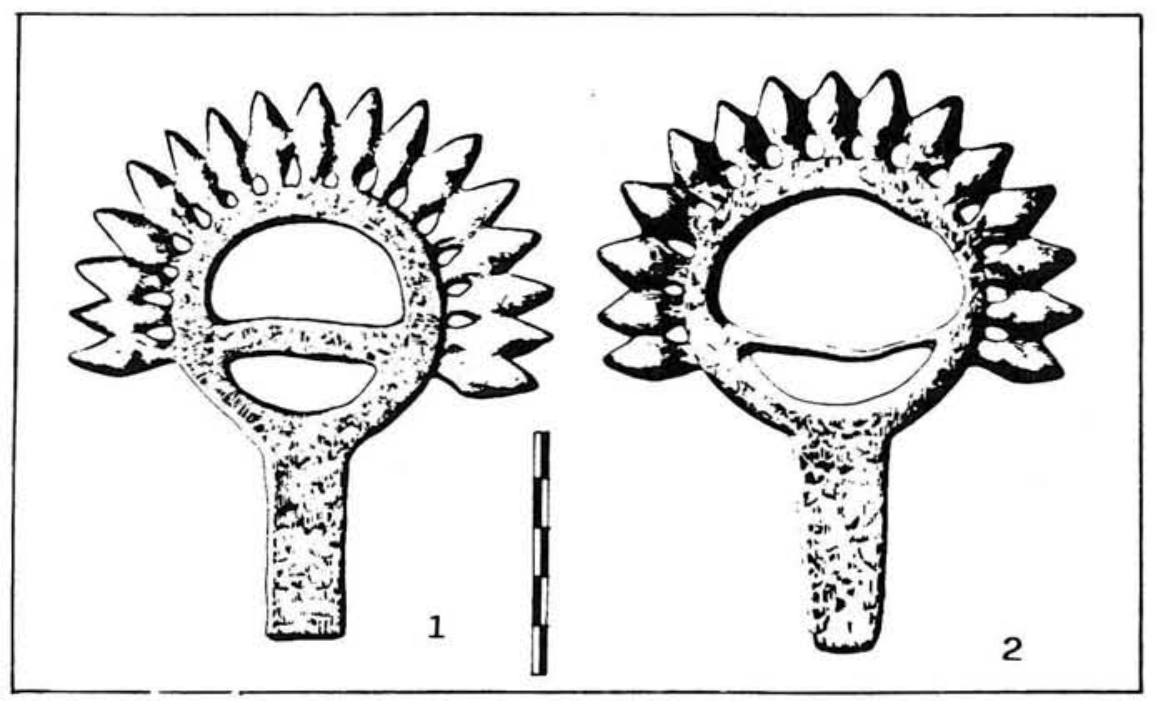

Figura No 7.- 1) Alcacer Do Sal 2) Museo Arqueológico de Barcelona (Fernández-Miranda y Olmos).

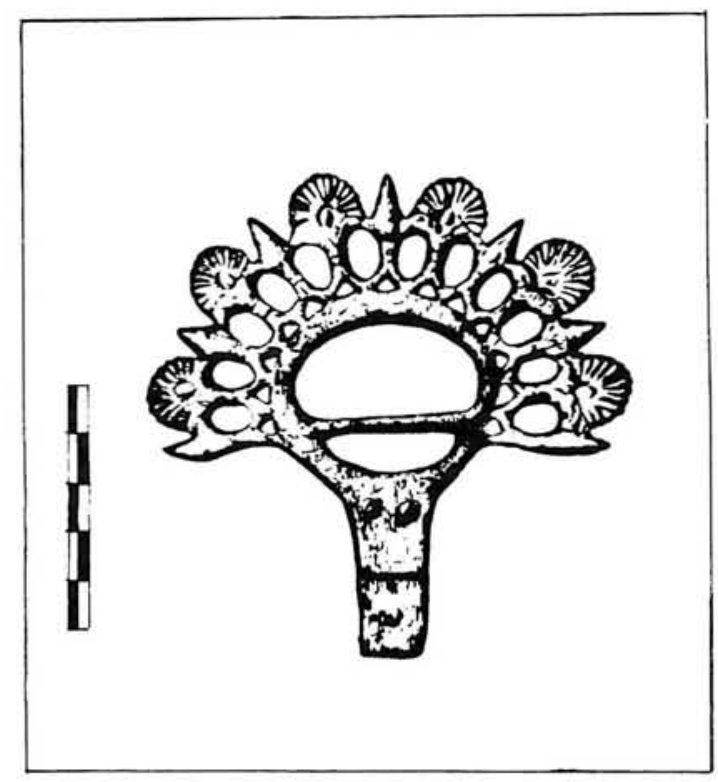

Figura No 8.- Colección Vives. (Fernández-Miranda y Olmos). 

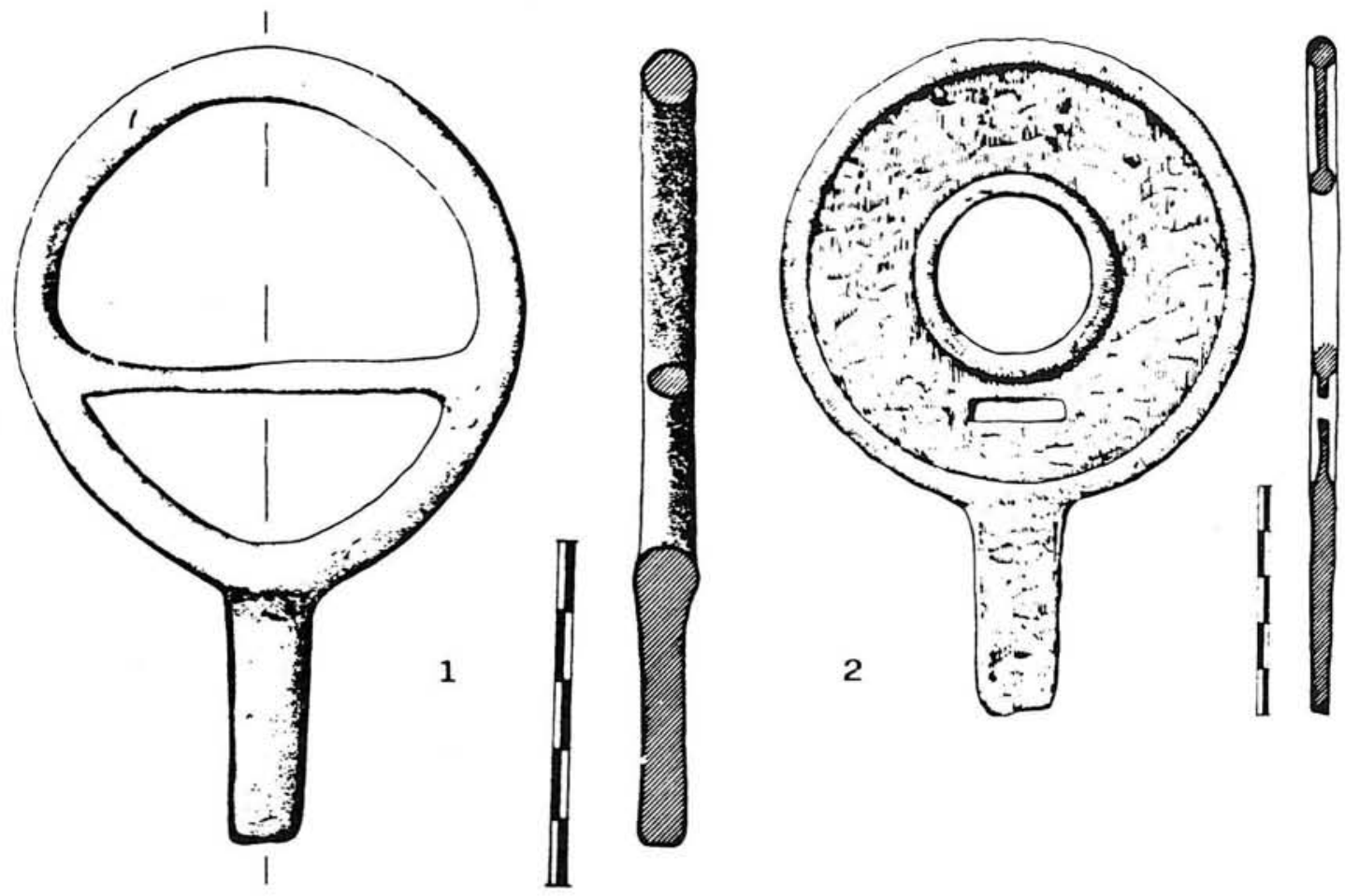

Figura No 9.- 1) Albodoluy. 2) La Joya.

mente en la casa no 3 del Peñón de la Reina (Almería), perteneciente a la fase III-b del poblado (Fig. 9, 1), y datado a fines del siglo VIII y principio del VII a.C. (Martínez-Botella, 1980, 302). La descripción de la planta de la cabaña: ovalada, con zócalo de piedras, restos de hoyos de poste y banco corrido de tapial por su cara interna (Martínez-Botella, 1980, 177) nos recuerda a otras construcciones del yacimiento orientalizante de Montemolín, con una estructura oval parecida a la descrita aunque de mayores dimensiones, y también fechada por sus elementos cerámicos, en el paso del siglo VIII al VII a.C. (Chaves-de la Bandera, 1991, 703). Este paralelo que podría avalar la antigüedad de las estructuras, que se mantienen en uso durante el resto del siglo VII a.C., como señalan otros objetos metálicos aparecidos en la Casa n 3 de Alboloduy, como son las fíbulas de doble resorte, de amplia difusión por otros yacimientos de este período (Martínez-Botella, 1980, 303).

- En el SEGUNDO SUBTIPO, incluímos los pasarriendas de la tumba no 17 de La Joya (Garrido, 1978, 76), piezas circulares con orificios centrales también con señales del desgaste, y ranuras y apéndices rectangulares, que sólo presentan un ligero engrosamiento del borde como elemento decorativo (Fig.9, 2). Estas piezas, fueron también recogidas en los estudios posteriores (Almagro, 1979, 184; Fernández- Miranda y Olmos, 1986, 90), aceptándose de forma global la cronología propuesta por el excavador de la necrópolis de fines del siglo VII y siglo VI a.C. para las tumbas con restos de carros y arreos de caballos. 
- EL TERCER SUBTIPO lo formarian piezas de carácter más simple en cuanto a su ornamentación, como son los pasarriendas circulares de las lanzas de carro de Maquiz (Jaén), que siguen la tradición de las cabezas de felino de La Joya (Fernández-Miranda y Olmos, 1986, 94). Sólo se conserva completo uno de los cuatro pasarriendas, en la cabeza de bronce $n^{\circ} 4$ de Maquiz (Almagro, 1979, 181), que consiste en una cabeza de lobo con un fuerte aro que sería utilizado con este fin (Fig. 10,1), si bien Fernández-Miranda, muestra ciertas dudas al respecto por su difícil colocación en el carro, a la vez que señala la dificultad existente a la hora de situar cronológicamente estas piezas, que, aunque siguen una tradición del siglo VI a.C. en las representaciones grabadas (centuria en la que podríamos situar también las cabezas de felino de Portixol en Ampurias), en Maquiz podrían datarse en un momento posterior por su tratamiento (1986, 96).

El último ejemplar que situaremos en este subtipo, también fue recogido por Almagro en su trabajo sobre este tema $(1979,194$ y fig. 13 a), y se trata de una abrazadera con un pasarriendas circular, perteneciente a un gran lebes de bronce de una tumba de Cástulo, fechado por este autor en torno al siglo VII a.C. (Fig. 10,2).

A la hora de establecer una posible evolución cronológica de estos pasarriendas, chocamos con una serie de problemas como la descontextualización de las piezas con elementos decorados, e incluso, en algunos casos, al desconocimiento de sus lugares de procedencia, ya que constituyen los fondos antiguos de museos o colecciones particulares. Por ello, debemos recurrir al examen estilistico de las piezas.

Por lógica, el ejemplar más antiguo, se correspondería con el que presenta los motivos vegetales más detailados, es decir, con una mayor pureza en la representación de los temas orientales. Este ejemplar (perteneciente a la colección. Vives), se fecha entre el 700 y el 600 a.C., y evolucionaría hacia la simplificación en modelos como los de Alcacer do Sal y el del Museo Arqueológico de Barcelona, representando los ejemplares de Ubeda, el último paso en esta estilización de capullos de loto. El paso siguiente lo constituiráan las piezas sin decorar de Cástulo, Cancho Roano y Alboloduy, avalado por las fechas tendentes al siglo V a.C. del yacimiento extremenio.

Sin embargo, y para destacar la dificultad que supone la cronologia basada exclusivamente en paralelos estilísticos, la aparición en un contexto estratigráfico de la pieza de Alboloduy, datada por otros materiales, supone la coetaneidad de todos estos tipos desde fines del siglo VIII hasta principios del siglo VI a.C., momento constatado para las tumbas de la necrópolis de la Joya.

\section{ELEMENTOS METALICOS DE LOS ANIMALES DE TIRO}

A) BOTONES CONICOS: No hemos encontrado en la bibliografía consultada, ningún ejemplar que podamos situar como paralelo exacto de las piezas de Ubeda la Vieja, con una rica y compleja decoración estrellada. Sin embargo, tenemos constancia de otros botones similares, aunque más simples, relacionados, en algunos casos, directamente con otras piezas de atalajes de caballos, que permiten también asimilar estos ejemplares al resto de elementos pertenecientes al posible carro orientalizante de esta localidad giennense (Fig. 11).

- Botones de bronce de Cancho Roano. son numerosos las piezas que este yacimiento ha proporcionado (Fig. 12). Algunos de ellos, ya fueron recogidos antes de las excavaciones de Maluquer (1981, 71), pero a medida que se fueron sucediendo las campañas de excavación, su número fue aumentando de forma espectacular, llegando a alcanzar la cifra de 175 piezas al finalizar la nove- 

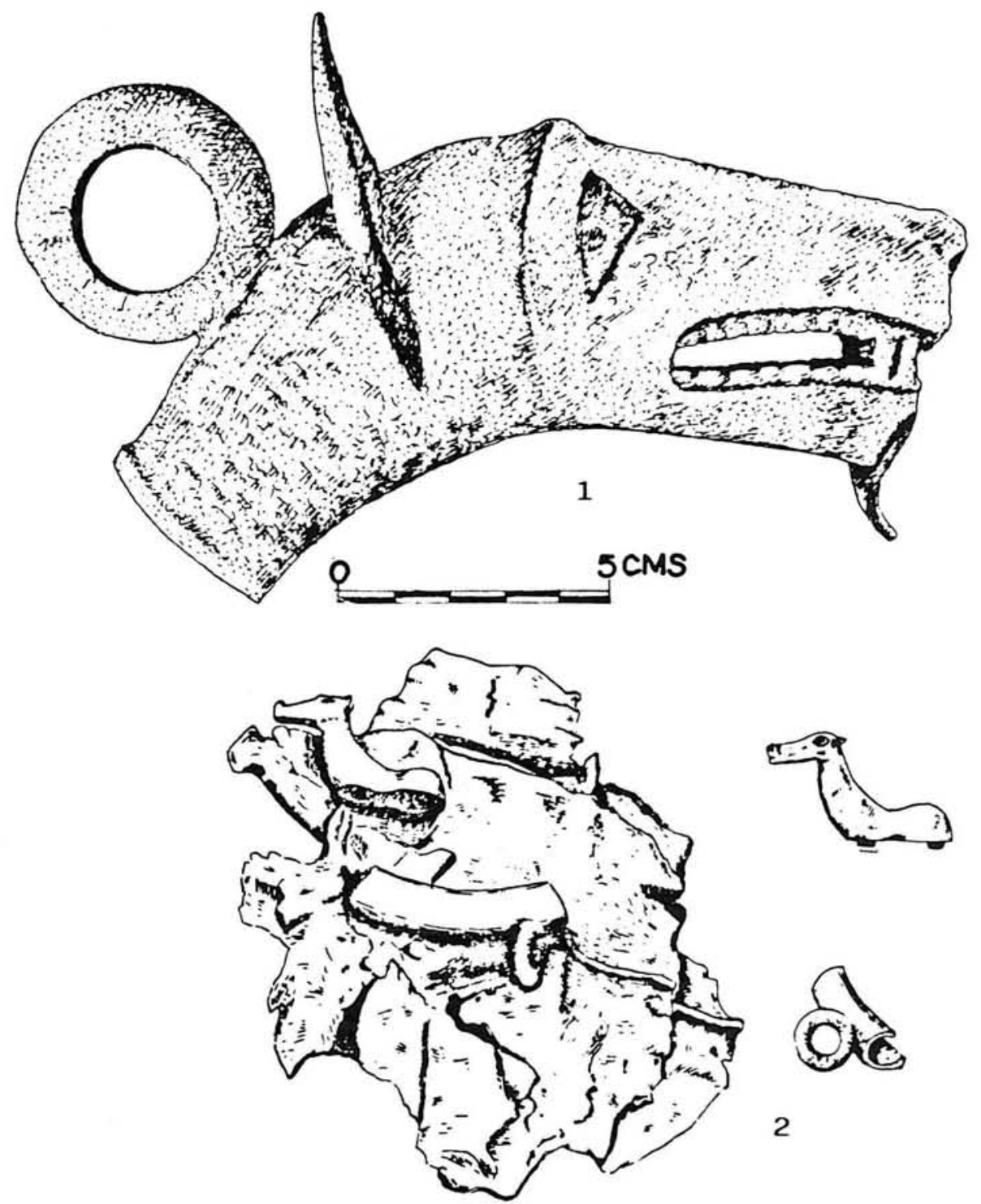

Figura No 10.- 1) Máquiz (Almagro). 2.- Cástulo (Almagro). 


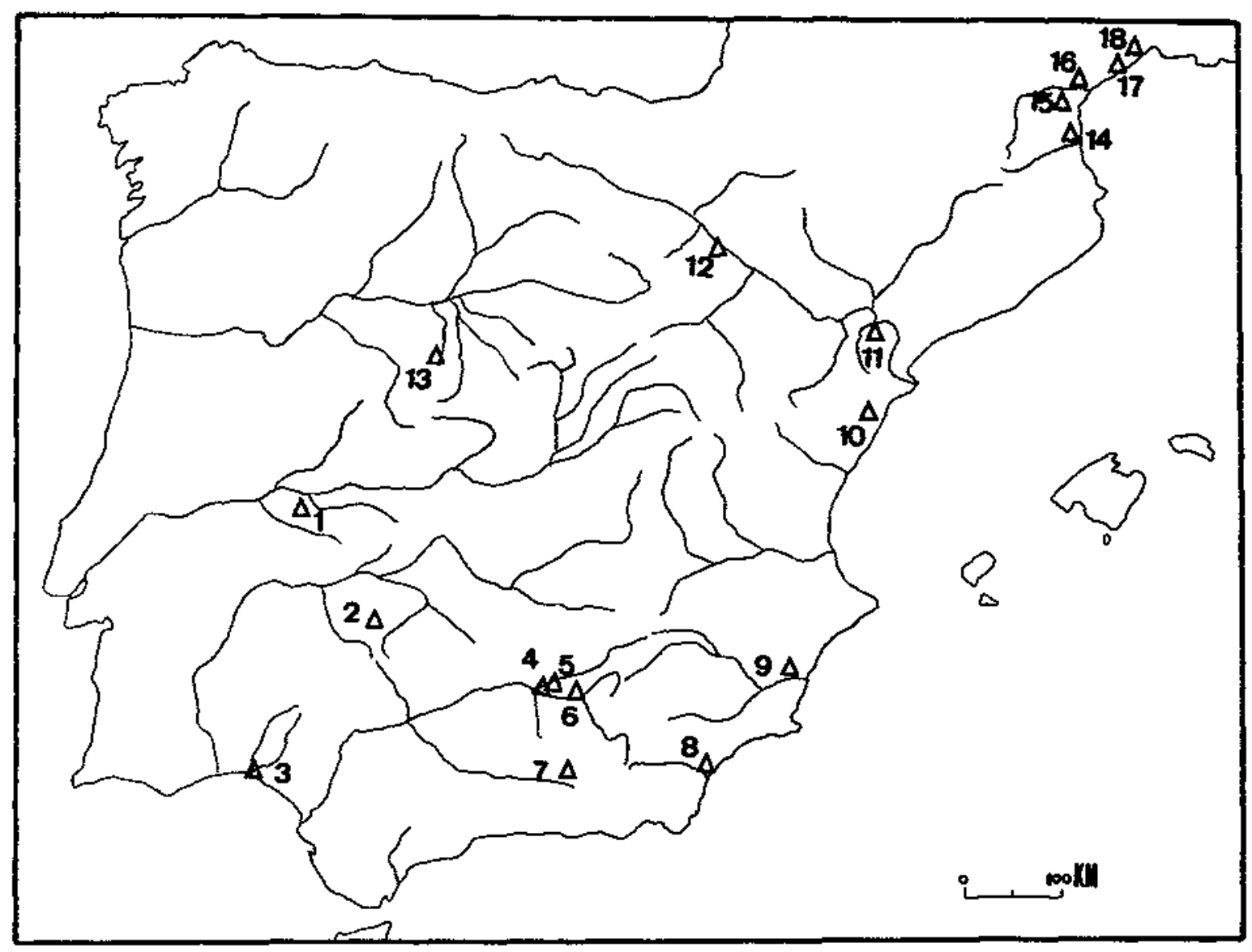

1.- Cabezo de Araya.

2.- Cancho Roano.

3.- Ria de Huelva.

4.- Estacar de Robarinas.

5.- Molino de Caldona.

6.- Ubeda.

7.- Fonelas.

8.- Villaricos.

9.- Peña Negra.
10.- Solivella.

11.- Tossal Redo.

12.- Cortes.

13.- Sanchorreja.

14.- Las Fados.

15.- Roc de Buffens.

16.- Grand Bassin I.

17.- Rieu-Sec.

18.- Belarga.

Figura No 11.- Mapa de dispersión de los principales yacimientos con botones cónicos. 

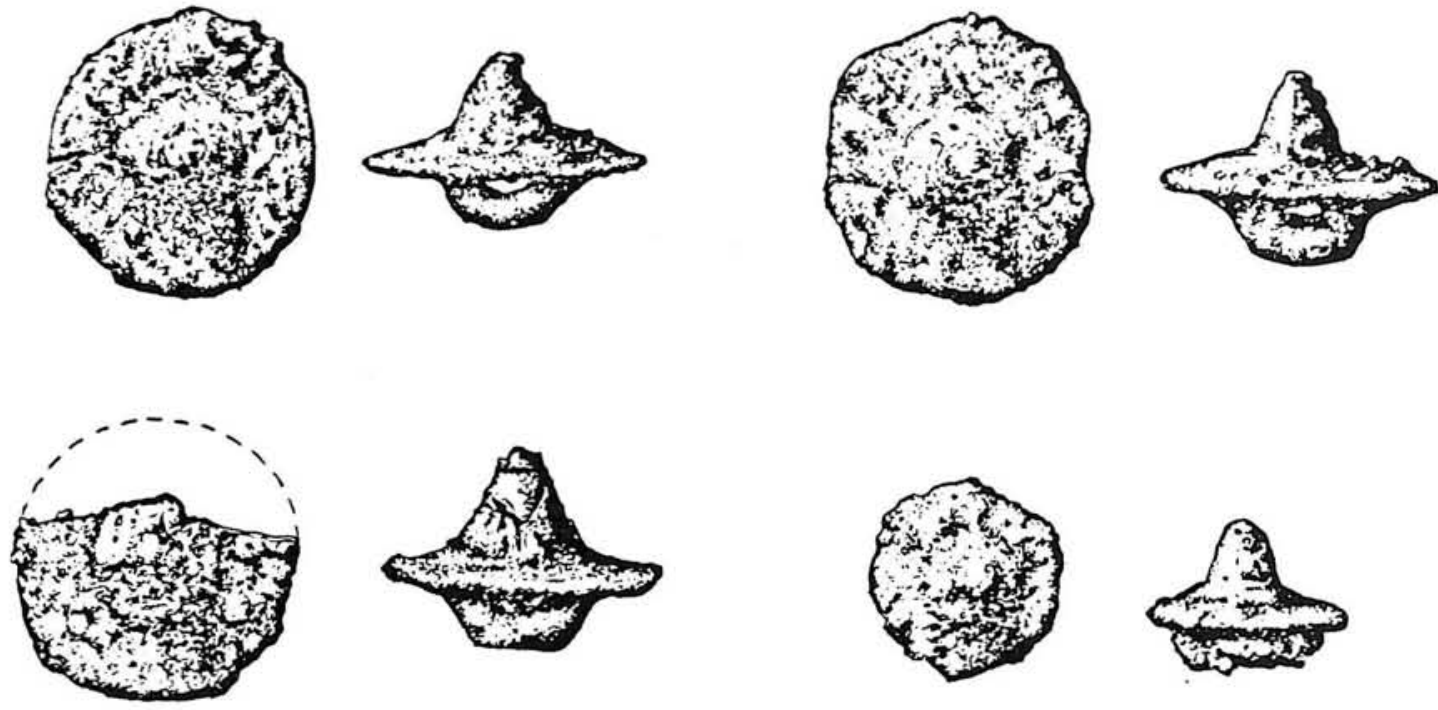

Figura No 12.- Cancho Roano (Maluquer).

na campaña en 1982, demostrando la existencia de al menos cuatro atalajes en el yacimiento, si consideramos un número de entre 45-50 para cada guarnición, según su autor $(1983,63)$.

Técnicamente estos botones fueron fundidos a molde, y presentan un travesaño inferior muy saliente en forma de arco. Responden a cuatro módulos diferentes de tamaño, según el lugar del cabezal donde fueran colocados (Maluquer, 1981, 107).

En cuanto a la cronología del yacimiento, ya hemos visto como la cerámica griega utilizada por Maluquer para fechar este palacio, sólo es válida realmente para situar su destrucción a finales del siglo $\mathrm{V}$ a.C., pero otros materiales aparecidos, como marfiles, un alabastrón o la pieza de bocado que se relaciona con el "Bronce Carriazo", nos hablan de una fase anterior, constatada también en la misma planta del edificio, que sigue la tradición sirio-palestina de inicios del I Milenio, como vemos en los monumentos de Tell Astana o Tell Tayanat (Almagro, 1990, 101-04)

\section{- Botones de Cástulo:}

1.- Hallazgo en el pozo del Conjunto F de Estacar de Robarinas. Ejemplar de difícil datación, ya que la zona de la necrópolis muestra una secuencia desde el siglo VII al IV a.C. (BlázquezRemesal, 1975, 657 y Lám. VIII, 1).

2.- Hallazgos de la Sepultura $n^{\circ} 1$ (con un fuerte vástago) y no 2 de la necrópolis del Molino de Caldona (Fig. 13, 1), fechada por sus excavadores a fines del siglo V a.C. por las fíbulas anulares que acompañan los ajuares de las tumbas (Arribas-Molina, 1968-69, 168 y 170, figs. XVIII, 8 y XXVII, 6).

- Botones de bronce de Villaricos: (Fig. 13, 2) proceden de sepulturas de incineración correspondientes a su Grupo III [Siret, 1906, 84 y Lám. XVII 52 (2) y 58 (2)]. 


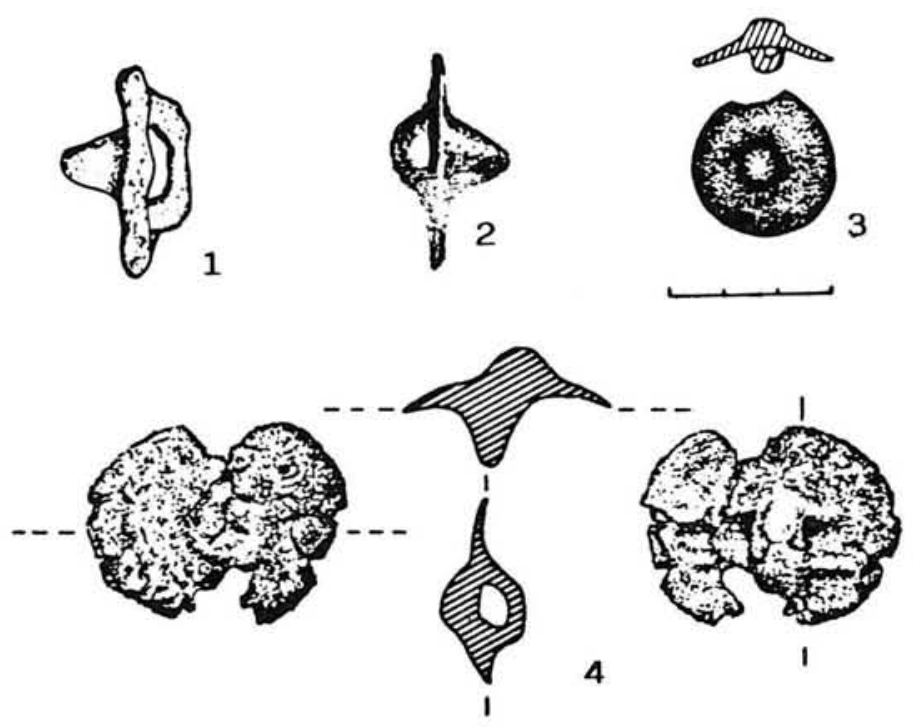

Figura No 13.- 1) Cástulo (Arribas): 2) Villaricos (Siret). 3) Peña Negra (González Prats). 4) Fonelas (Ferrer).

- Botón cónico de Peña Negra: Pertenece al Corte D del Sector II, que es un nivel revuelto, por lo que podría corresponder a su fase del Bronce Final (850-675 a.C.). Apoyando esta opinión, estaría la prueba del análisis metalográfico del botón, que ofrece un 99, $2 \%$ de cobre, y un mínimo componente de arsénico, y no estańo, como será lo frecuente en la Fase Orientalizante del yacimiento (Fig. 13, 3).

Presenta un diámetro de $2,7 \mathrm{~cm}$, y lleva soldado un puente en su parte inferior, que deja una zona libre para su colocación al arreo del caballo, en el caso de que se utilizara para este fin (González Prats, 1983,178 y 249 , fig. 39, 5).

- Doce botones de bronce de La Ría de Huelva: Presentan forma cónica y travesaño en su extremo inferior. Sus dimensiones oscilan entre los $3 \mathrm{~cm}$ de altura y otros $3 \mathrm{~cm}$ de anchura en su base (Almagro, 1937, 137 y Lám. V).

- Botón de bronce de Fonelas (Granada), en forma de cabeza de seta (Fig. 13, 4). Se encuentra en un mal estado de conservación, y pertenece al nivel superior de un enterramiento megalítico, fechado en torno al siglo VIII a.C. por sus paralelos de la Ría de Huelva y el Cabezo de Araya (Ferrer, 1977,186 y fig. 10, 2).

- Botón de bronce de La Solivella, de forma discoidal y vástago que se ensancha en su extremo. Fletcher (1965, 18 y Lám. V, 3) fecha al yacimiento entre los siglos V-IV a.C. por otros paralelos; sin embargo, al tratarse de un material recogido en superficie, y por la presencia de otros elementos como fíbulas de doble resorte (presentes en un $6,70 \%$, y que suelen corresponder a cronologías más altas) junto a un escarabeo del taller de Naukratis datado en la primera mitad del siglo VI a.C. (Padró, 1977, 501), la fecha del botón, podemos situarla en un momento anterior. 


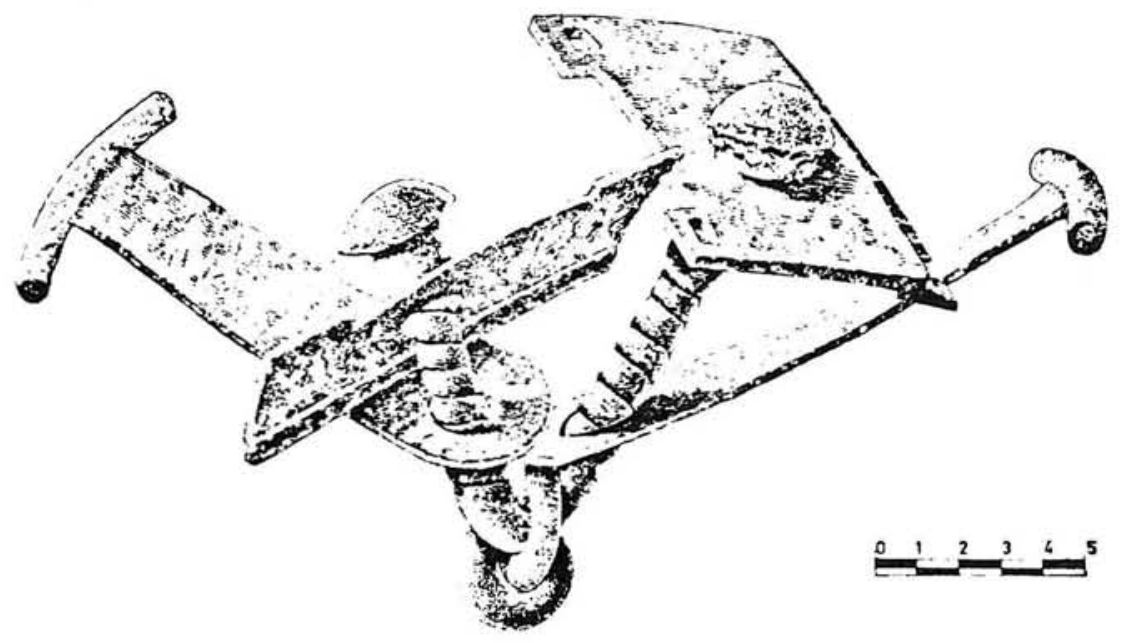

Figura No 14.- La Joya (Garrido).

- Botones de Cortes de Navarra: Maluquer nos muestra algunos ejemplares pertenecientes a la Fase PIIIa del yacimiento (1958, Lám. XVII, A), y otros correspondientes a la Fase PIIb, fechada entre el 725 y el 550 a.C. por la presencia de otros materiales como las fíbulas de doble resorte (1954, 137, Lám. LI, 1).

- Más al interior peninsular, contamos con un ejemplar documentado en el nivel inferior de Sanchorreja, fechado en torno al siglo VII-VI a.C. por Maluquer (1958, Lám. XVII, B).

- El resto de botones de bronce de este tipo, aparecen en yacimientos de la zona catalana y del Languedoc (González Prats, 1983, 250-51), situados en la misma línea de penetración de otros materiales de influjo claramente orientales, como las fíbulas de doble resorte, las puntas de flecha de arpón, o los escarabeos egipcios y egiptizantes, que nos hablan de un siglo VII-VI a.C. para toda la región.

B) BOCADOS DE CABALLO: Tampoco hemos encontrado ningún paralelo exacto de las dos piezas de Ubeda la vieja , sin embargo, analizando los ejemplos que nos ofrece la bibliografía actual, hemos encontrado algunos semejantes que ponen en relación estos bocados de caballo con otros ejemplares orientalizantes:

- Filetes articulados de la tumba no 17 de La Joya: (Fig. 14) el carro de esta sepultura, estaría tirado por dos caballos, ya que contamos con el hallazgo de dos filetes compuestos por dos barras de cañón retorcidas del estilo de las aparecidas en Ubeda, que engarzarían mediante argollas como 


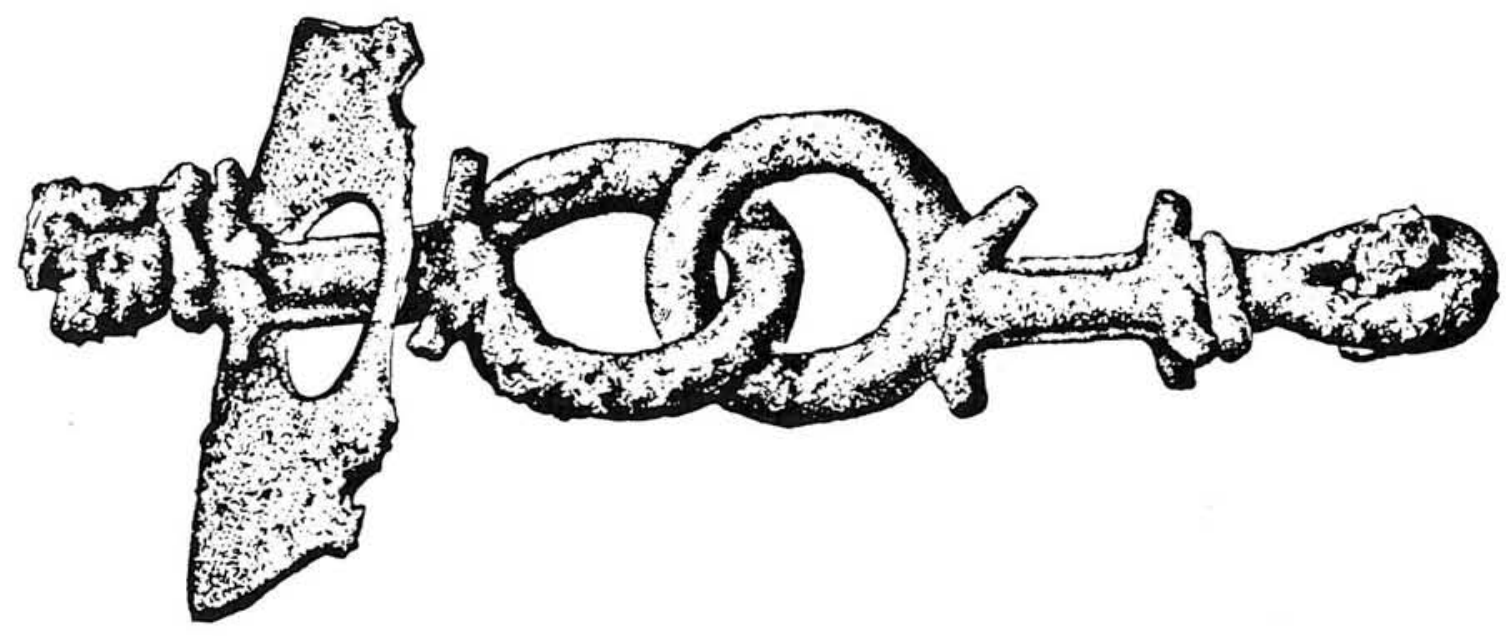

Figura No 15.- Cancho Roano (Maluquer).

las presentadas, pero terminadas, en este caso, en apéndices cilíndricos (Garrido, 1978, 87; Almagro, $1979,188)$ y no en otras dos argollas menores como las piezas A. 4 y A.5 del catálogo.

Este tipo de bocado lo completan unas camas laterales compuestas por placas rectangulares y dos tirantes en "T" desconocidos hasta el momento en otros puntos del Mediterráneo (Fernández Miranda y Olmos, 1986, 93).

- Otras piezas que se asemejan a las presentadas, son los tres filetes encontrados en las excavaciones de Cancho Roano: (Fig. 15) el primero de ellos (recogido gracias a los trabajos agrícolas) muestra tallos rectos, diferentes a los de Ubeda, que están trenzados al estilo de los de La Joya, pero cuenta en este caso con unos bucles en sus extremos al modo de las argollas menores de los ejemplares presentados (Maluquer, 1981, 290 y Fig. 10). Destaca el segundo filete de Cancho Roano, además de haber sido encontrado en el transcurso de la séptima campaña de excavación, y no de modo fortuito, por conservar en uno de sus bucles una de las anillas de bronce para las riendas de cuero del carro (Maluquer, 1983, 52 y Fig. 9). El tercer filete, a pesar de encontrarse roto (1983, 54), es significativo por el sogueado que presenta en el único tallo conservado, acercándose de esta forma al ejemplar de Ubeda, que pensamos como posible tipo intermedio entre los aparecidos en La Joya (tumba 17, fechada como hemos visto a fines del siglo VII a.C.), y los ejemplares de Cancho Roano, monumento, que como hemos indicado, presenta su máximo esplendor durante el Horizonte Orientalizante, y cuyo final tenemos constatado por el nivel de incendio de fines del siglo $\mathrm{V}$ a.C. (Almagro-Gorbea, 1990, 101).

- Tenemos constancia de otros hallazgos de bocados de caballo, en otros yacimientos con dataciones más tardías y dentro ya claramente del momento ibérico. Están fabricados en su mayoría 
en hierro, y no en bronce como en los casos anteriores. Algunos de estos objetos, son los encontrados en la necrópolis de Estacar de Robarinas (Cástulo), formando parte del ajuar de guerreros, si atendemos al resto de materiales que los acompañan (Blázquez-García-Gelabert, 1985, 539). Otros de ellos, son los aparecidos en la necrópolis de El Cigarralejo (Murcia), formados por barras cortas y gruesas que se articulan con anillas fijas, y que han sido descubiertos en tumbas fechadas por Cuadrado a finales del siglo V a.C. (1987, 93 y Figs. 145, 203, 222). Otros posibles restos, son los fragmentos citados por Presedo, aparecidos en un ustrinum de la necrópolis de Baza fechado a principios del siglo IV a.C., pero sin ningún dibujo o descripción que nos aclare la naturaleza de estos elementos $(1982,264)$.

Para una posible reconstrucción de los cabezales y atalajes con los que irían enjaezados los cabaIllos, podemos recurrir a otra fuente que nos brinda la Arqueología: las representaciones escultóricas de estos animales, que muestran en algunos casos arreos semejantes a los presentados en este estudio, con discos y rosetas que completan la decoración de sus cabezadas, como vemos en la cabeza de caballo de Fuente de la Higuera (Fig. 16, 1), adornada con estos discos y una gran frontalera (Llobregat, 1972, 146), y que sirve de modelo a Maluquer para representar el sistema de atalajes y enlace de correas en los caballos del Palacio-Santuario $(1981,105)$. Este sistema de discos y zosetas, también está presente en otros ejemplares de variada cronología, como en la cabeza de arenisca de La Covatilla (Marchena), con placas circulares en forma de rosetas de nueve pétalos y botón central (Fig. 16, 2), de ascendencia claramente oriental en el mundo asirio del siglo VIII a.C. (de la Bandera, 1979-80, 397), y que a nosotros se nos antojan muy parecidas al vástago cilíndrico rematado por una chapa en forma de roseta de ocho pétalos (Fig, 16, 3), que apareció junto a los bocados de caballo de la tumba 17 de La Joya (Garrido, 1978, 84 y Fig. 48, g). Sin embargo, aunque otros elementos como la forma de los ojos, le recuerde la plástica griega del siglo VI 2.C., esta cabeza se fecha entre los siglos III-II a.C. por la ausencia del bocado (de la Bandera, 1979-80, 392 y 397), lo que viene a destacar la tradición que este tipo de arreos mantiene durante mucho tiempo. Hay que constatar que existen también algunos ejemplos de caballos sin representación del bocado, en otros soportes como el jarro de bronce de la tumba no 18 de La Joya, de cronologia más alta (Garrido, 1978, 131-35), aunque pueda deberse en este caso a la dificultad que encontraria el artesano en representar este detalle del bocado en un asa de estas características (3).

Otra cabeza escultórica con esta representación de rosetas pertenece a un conjunto de cabalio y guerrero del yacimiento de Cerrillo Blanco (Porcuna), que presenta un puñal y unas fáleras que pueden ser fechadas desde fines del siglo VI a últimos años del V a.C. (González Navarrete, 1987, 22 y 51 ). También contamos con la cabeza no 34 de su catálogo, que presenta fáleras y camas laterales en forma de media luna, como en el conjunto de Cancho Roano (González Navarrete, 1987, 184-88).

Otras representaciones escultóricas donde podemos apreciar el enjaezamiento de estos caballos, están presentes en el yacirniento de El Cigarralejo (Murcia), pertenecientes a las tumbas de este complejo funerario. Las cabezadas son de cuero, al estilo de los caballos ibéricos, con protección en la nuca, frente y morro, y muestran en algunos casos los extremos del filete de sus bocados (Cuadrado, 1984, 259-62).

(3) Sugerencia que amablemente nos indicó la Profesora Ma.L. de la Bandera cuando le comunicamos nuestras inquaiecudes sobre esre paricular. 

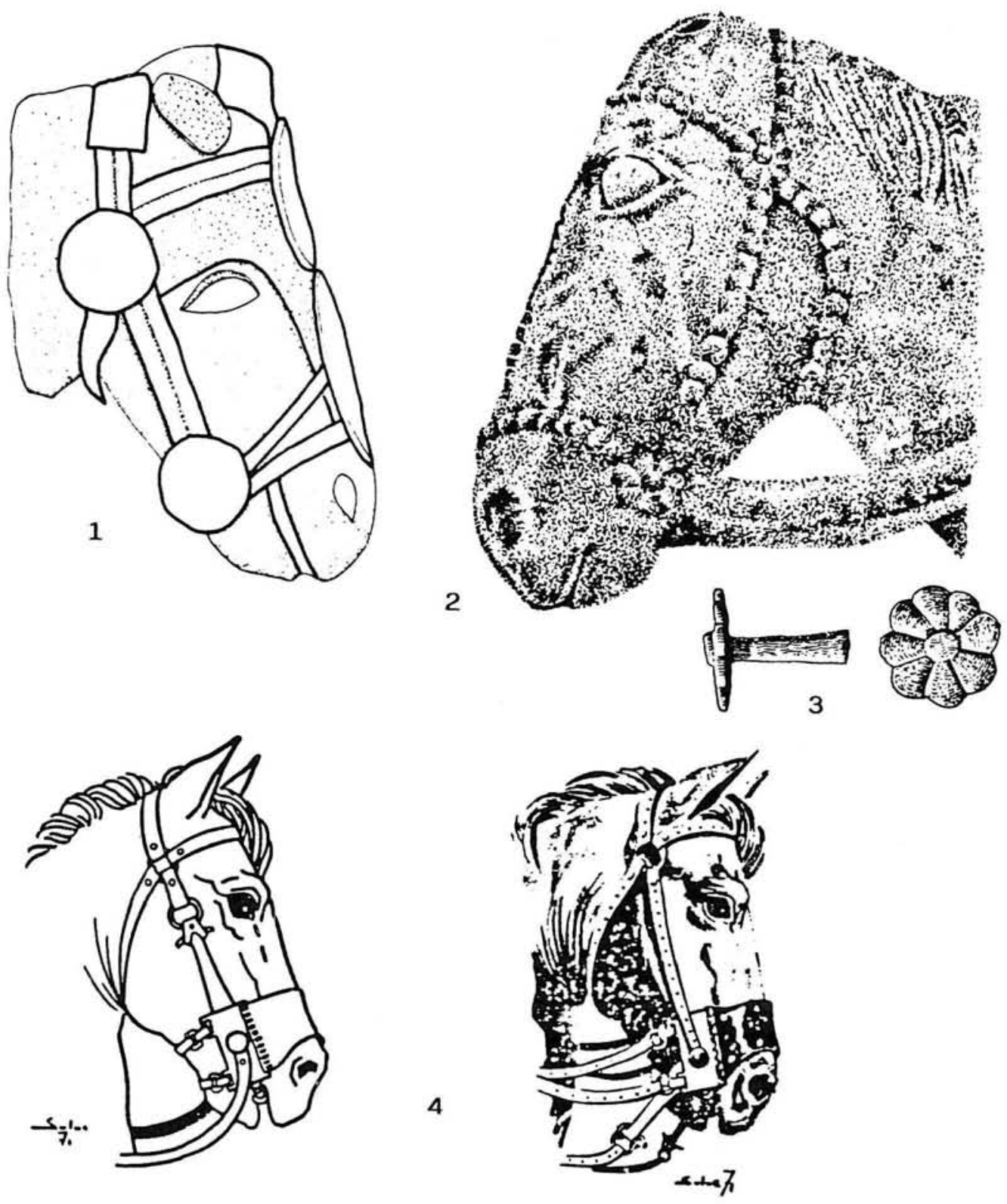

Figura No 16.- 1) Fuente de la Higuera (Maluquer) 2) La Covatilla (De la Bandera) 3) La Joya (Garrido) 4) La Joya (Garrido). 
De esta forma, y debido a la ausencia destacada en los dos conjuntos presentados de piezas tan singulares como las camas laterales (del tipo de Cancho Roano, con cabecitas de caballo, o un "despotes o potnios" bifronte), o las placas rectangulares y tirantes de La Joya (Fig. 16, 4), o bien elementos decorativos como los discos y rosetas analizados, nos parecen ambos sistemas (Garrido, 1978, Fig. 53, 2; Maluquer, 1981, Fig. 40), válidos para nuestros conjuntos, hasta que futuras investigaciones, aporten datos más concluyentes en este sentido.

C) PIEZA INDETERMINADA: Como hemos señalado en el capítulo de descripción del catálogo, no conocemos hasta el momento de su redacción, ningún otro elemento que se le asemeje y aclare nuestras dudas sobre la posible función de estas dos piezas. Sin embargo, queremos adelantar algunas hipótesis, abiertas por supuesto a cualquier tipo de corrección, que nos sugiere el mero estudio morfológico de los materiales.

Pensamos fundamentalmente en dos posibles usos: el primero de ellos viene motivado por la ausencia constatada en el conjunto, de piezas catalogables como camas laterales de bocado, al estilo de las encontradas en otros yacimientos que han aportado materiales similares (ya sean botones, filetes, pasarriendas, etc). Sin embargo, aunque las piezas de Ubeda, presentan un orificio central y unas argollitas por donde podrían sujetarse las barbadas [pensemos en las placas rectangulares de la tumba $\mathrm{n}^{\circ} 17$ de La Joya, con ranuras para ese fin (Garrido, 1978, 87)], el diámetro de este orificio cencral (22-23 mm.) nos resultaría desproporcionado en relación al menor diámetro de los cañones de los filetes encontrados en la misma colección, (oscilan sobre los $11 \mathrm{~mm}$.), diámetro semejante a los filetes de Cancho Roano, pero sin contar en nuestro caso con sus apéndices apuntados para mantener enhiestas sus placas laterales, y con orificios centrales de unas medidas similares a las de Ubeda, pero muy alejadas de éstas tipológicamente (Maluquer, 1983, 52; Ibid., 1981, Fig. 38).

La segunda hipótesis que nos sugiere el estudio de estas piezas es su posible uso como pasarriendas circular, que, en este caso, pertenecerían a otro carro del mismo yacimiento, hecho que de confirmarse, vendria a sumarse a la ya gran diversidad de tipos sin decoración. De esta forma las argollas que van unidas a estas placas pueden funcionar como suplente de los vástagos que las fijarian al carro o al animal, dejando el orificio central para el paso de las riendas o viceversa.

Esto nos parece poco probable debido al número de piezas analizadas en este conjunto, que suponen la existencia de un carro con tres de sus cuatro pasarriendas con su doble tito de cabailo, (los dos filetes aparecidos en el mismo conjunto) y dos de sus cuatro camas laterales, si consideramos realmente que sea ésta la finalidad para estos elementos, así como por lo extraño y difícil que resultaría explicar su colocación en la caja del carro sin la ayuda del vástago.

En cuanto al tiro de caballos, consideramos muy probable su similitud al tipo de atalaje, rico y variado, que presentan los animales de Cancho Roano, al contar en el ejemplo de Ubeda, con botones de bronce similares, aunque con una decoración más refinada. La aparición en Cásrulo de otras piezas interpretadas como camas laterales de bocado, idénticas a las aparecidas en Cancho Roano (Maluquer, 1983, 63), unido al nuevo hallazgo de otros elementos considerados como pasarriendas sin decoración, procedente también de Cástulo (Fundación Alhonoz), y semejantes a la mencionada por Maluquer $(1981,408)$, nos indican que existe cierta vinculación entre la zona extremeña y la giennense a través del Guadalquivir, quedando esta zona y sus importantes necr6polis (Cerrillo Blanco, Mengíbar, Cástulo) como eje de una importante vía de comunicación cultural entre el Bajo Guadalquivir y la zona de Levante, donde contamos con yacimientos como los Saladares o Pefia Negra (Ruiz Delgado, 1989 b, 255). Ruta que, como ya hemos avanzado en otros estudios (Mancebo y Ferrer, 1988-89; Ibid., 1991 e.p.), se sigue con facilidad atendiendo a otros 
materiales de procedencia oriental como las puntas de flecha de arpón y los escarabeos, objetos de claro comercio fenicio en la Península (González Prats, 1983, 245-51).

\section{CONCLUSIONES}

Del análisis de los conjuntos presentados y de sus paralelos podemos inferir la existencia de dos carros "orientalizantes" evidenciados en el caso del conjunto B de Cástulo por tres de los cuatro pasarriendas que irían situados en el frontal de la caja del carro, idénticos a los encontrados en Cancho Roano y en el Peñón de la Reina, y, en lo que respecta a las piezas de Ubeda la Vieja (conjunto A), por tres pasarriendas decorados, así como las piezas del bocado y del cabezal de los cabalilos, con paralelos en piezas datadas con fiabilidad en yacimientos como La Joya.

Tanto el análisis estilistico como los paralelos bien fechados, sińan estos conjuntos en un margen cronológico amplio, entre los últimos años del siglo VIII y los primeros del siglo VII a.C. (para la pieza de Albodoluy), y principios del siglo VI a.C., fecha más baja estimada para la tumba 17 de La Joya. Es decir, podemos arribuir las piezas giennenses a un Horizonte Orientalizante Pleno, cuando se produce un rápido crecimiento económico entre las poblaciones tartésicas y su hinterland, debido sobre rodo, a una mayor demanda de metales y la consiguiente agilización del comercio, y por el establecimiento de artesanos fenicios que elaboran in situ las manufacturas de lujo, hecho que apreciamos en otros yacimientos como Peña Negra en la realización de sus cerámicas (González Prats- Pina, 1983, 125; González Prats, 1983, 273-74).

En la segunda mitad del siglo VII y fundamentalmente a partir del siglo VI a.C. se da una mayor abundancia de hallazgos tartésicos de tipo oriental en esta zona de la Alta Andalucia, lo que se traduce en una mayor complejidad social y una progresiva jerarquización de la sociedad (Aubet, 1977-78, 94).

Otra conclusión estrictamente tipológica, deducible de los datos aportados, es la posibilidad de identificación y difetenciación de los diversos tipos de carros protohistóricos peninsulares según sus restos materiales conservados, independientemente del contexto arqueológico en el que aparezcan (lo que suele ser infrecuente, ya que la mayoría son piezas aisladas en fondos de museos o de colecciones particulares).

Todos los conjuntos mencionados presentan como único elemento identificable del carro los pasarriendas, quizás las piezas más notables, por así decirlo, del vehículo, que sería sin lugar a dudas por entero de madera, razón por la cual sólo se conservan los restos metálicos. Junto a éstos, las piezas de los cabezales del caballo, irían montadas sobre cuero, del que tampoco han quedado restos. Cabe la posibilidad, creemos que abierca a nuevas interpretaciones, de que hubiese una selección de las piezas del carro y de los arreos, las más significativas, para su deposición en las tumbas o como ofrendas en los santuarios, y la reutilización de otras partes, como las ruedas, por la mayor complejidad en su fabricación y su elevado coste. Esta hipótesis contempla la realización de un correjo ritual en el que, entre otros titos, se procedería a la deposición del difunto o de sus restos incinerados en la fosa o cista, con todas sus pertenencias más apreciadas, y entre ellas, el carro, que por sus características propias y su escasez, constituiría uno de los objetos de más valor, sinónimo de una situación social más privilegiada (Fig. 17). El carro, para su colocación en la sepultura, se desmontaría o bien sólo se depositarian una selección de piezas, las más significativas. Un hecho a tener en cuenta es que el tamaño de las tumbas (túmulo de los Higuerones, La Joya) hace dificil la colocación del carro incluso desmontado, y que los vehículos no se incineraron con el difunto, pues las piezas conservadas no están abrasadas (Garrido, 1978). 


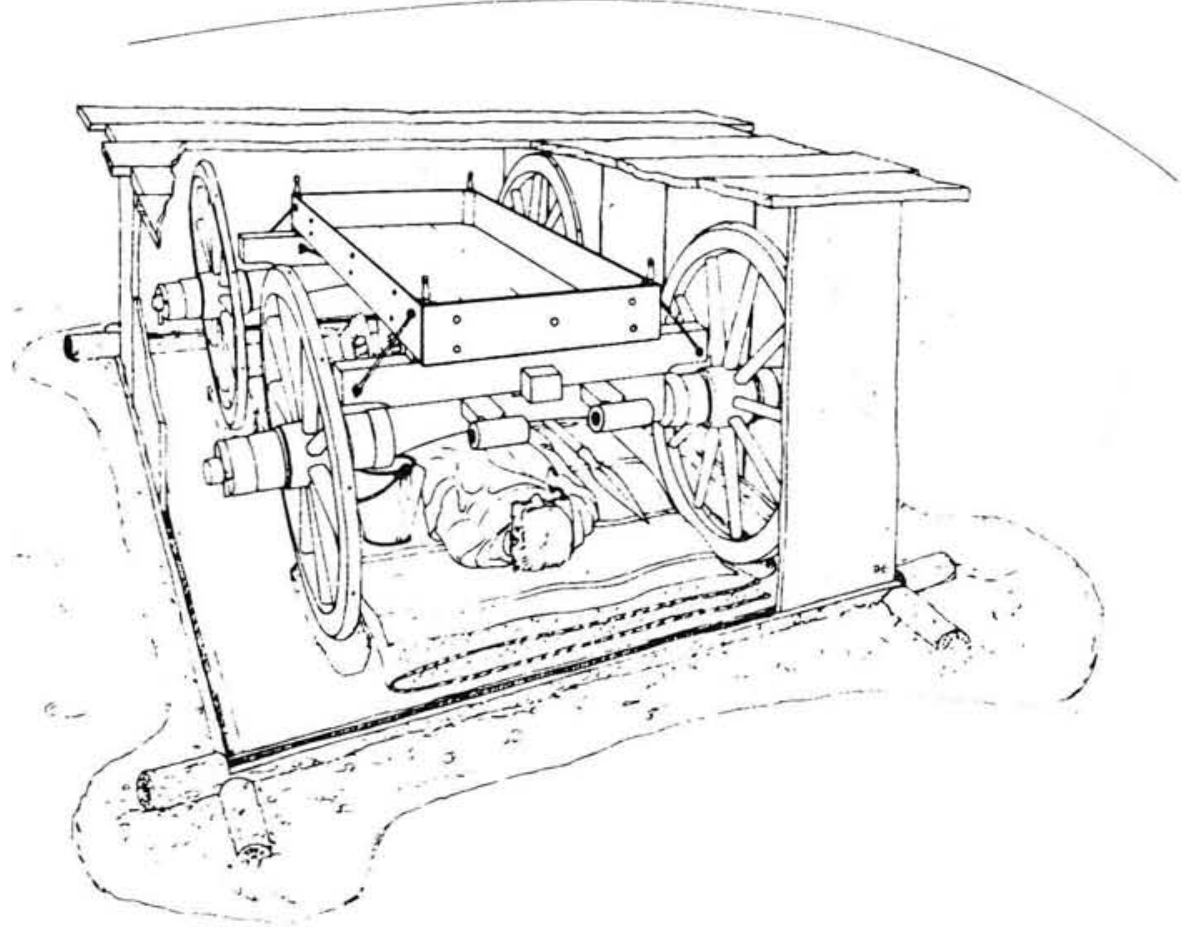

Figura № 17.- Reconstrucción de Túmulo funerario alemán con carro, procedente de Bell (Hunsruck). s. VI a.C. (Rheinisches Landesmuseum Bonn).

Lo que sí es evidente, es que los carros Ibéricos, descendientes por lo menos en cuestiones cronológicas de los Orientalizantes, dejan otro tipo de restos arqueológicos, siempre relacionados con las ruedas y con los atalajes de caballo. Son numerosos los fragmentos de metal, generalmente de hierros, asignables a remaches, bocines, refuerzos de ruedas, que aparecen en las necrópolis ibéricas del Sureste, con una cronología general que abarca los siglos V y IV a.C. Hay pues una diferenciación morfológica entre ambos tipos, diferencias que también se pueden inferir de la distribución de los hallazgos (Fernández Miranda-Olmos, 1986). Si los ejemplares de época Orientalizante se dispersan por el solar tartésico y por su hinterland: La Joya (Huelva), Cancho Roano (Badajoz), Alcacer do Sal (Portugal), Cástulo y Ubeda la Vieja (Jaén) y Albodoluy (Almería); los correspondientes al Horizonte Ibérico se concentran en las necrópolis bastetanas y oretanas del Sudeste: Toya (Cabré, 1924; Fernández Miranda-Olmos, 1986) en Jaén, Galera (Cabré, 1924), Mirador de Rolando (Arribas, 1967) y Baza (Presedo, 1982) en Granada, y El Cabecico del Tesoro (Fernández Miranda-Olmos, 1986) en Murcia. La explicación de este fenómeno pasa por una serie de características comunes, compartidas por ambos horizontes. La aparición de carros depende en gran medida de la suma de factores relacionados con la existencia de una sociedad jerarquizada, de corte aristocrático, con una clase superior, reducida numéricamente, que acumule en sus manos el poder económico, político y religioso. En definitiva, se conecta con la existencia de una demanda de artículos de lujo importados de difícil acceso y elevado valor.

Estos presupuestos se cumplen, como veremos posteriormente, en el caso del mundo tartésico orientalizante y en el horizonte ibérico del Sudeste. 
Orra conclusión que se extrae de lo expuesto hasta ahora es deducible del proceso de formación y definición de la sociedad tartésica, de sus características y de las diferencias regionales. Ubeda la Vieja y Cástulo son dos importantes centros de la Alta Andalucía, zona que tradicionalmente se situaría en el hinterland tartésico. Una justa valoración de estos yacimientos debe ir precedida de un análisis de la documentación arquueológica. En lo que se refiere a Cástulo es el centro más importante del Alto Valle del Guadalquivir por su emplazamiento estratégico (cruce de vías y cañadas ganaderas antiguas, que comunican el Valle del Guadalquivir, la Meseta, el Sudeste y Levante, y la costa mediterránea andaluza). Goza además de importantes recursos naturales: agua abundante, posibilidades agricolas, yacimientos mineros cercanos, etc. (Garcia-Gelabert, 1987, 30-31), y desde los años setenta está siendo excavado sistemáticamente, proporcionando en sus distintas áreas de necrópolis, poblado, y villa, una fuente inagotable de dacos arqueológicos que contemplan un poblamiento continuado al menos desde el Bronce Final hasta epoca Tardorromana.

El Horizonte Orientalizante se define en Cástulo por una serie de hallazgos:

- Necrópolis de Los Patos. En los niveles inferiores, debajo de la necrópolis ibérica, salieron a la luz tumbas de incineración con materiales cerámicos de imitación, relacionados con el Bajo Guadalquivir, y algunos objetos metálicos, como un broche de cinturón, fechado a mediados del siglo VII a.C. (Blázquez, 1982, 409-411).

- Necrópolis de Estacar de Robarinas. Con urnas de incineración decoradas con motivos orientales y ajuares con armas de hierro, thymiaterion, figurillas hathóricas de un léber, cerámica tipo Cruz del Negro, y cama de caballo semejante a una de Cancho Roano, que nos sitúa en el siglo VII a.C. (Blázquez, 1982, 415-16; Aubet, 1984, 450). Tambiên fưe excavada una tumba monumental escalonada con esculturas animalísticas.

- Túmulo de Los Higuerones. Gran monumento funerario de forma escalonada que cubría una cista expoliada. En las cercanias, se descubrió en un hoyo posiblemente ritual, un rico ajuar con materiales de claro sabor oriental: thymiaterion y caldero propios de un "servicio ritual" fechados también en el siglo VII a.C. (Blázquez, 1982, 417; García - Gelabert, 1986, 34).

- Santuario de La Muela. Es un complejo de edificios en los que se diferencian dos fases. La primera, se corresponde con una fosa de consagración, y la segunda, supuso la construcción de un edificio con un gran patio y una estancia cerrada a la que se accedía por una rampa. En este lugar se consumían y cocian animales sacrificados, y se hacían ofrendas vegetales y líquidas. Tanto el ritual como la planta, según sus excavadores, tienen paralelismo tanto en otras construcciones similares en el área tartésica (Entremalo, Carambolo...) como en Creta y Chipre (Blázquez, 1982, 424; Ibíd, 1986 a., 69; Blázquez y otros, 1984, 244).

De estos datos se deduce que el Horizonte Orientalizante en Cástulo y, por extensión en la Alta Andalucía, se muestra tardío y con raices en la zona onubense y en la Baja Andalucía (Blázquez, 1982, 425; Nocere y otros, 1982, 193). Estas conclusiones pueden parecernos en un principio contradictorias si atendemos a una revisión superficial de los ricos ajuares de Escacar de Robarinas o de los Higuerones, o al complejo sacro de La Muela, que sugieren como han subrayado ya algunos autores, la existencia de una clase poderosa al servicio de la cual trabajan especialistas que conocen las técnicas de construcción y metalurgia orientales, directamente relacionados con el mundo 
semita peninsular (paralelos aproximados de las técnicas de construcción de La Muela en un muro de Toscanos, fechado en torno al 700 a.C.) (Blázquez, 1982, 426; Ibíd, 1986 a., 62). Estos hechos abogarían hacia una aculturación de las poblaciones del Alto Guadalquivir por la presencia directa de individuos- técnicos fundamentalmente de origen oriental-, la asimilación de rituales ajenos a la tradición indigena (entre los que se encuentra la utilización de los carros en los servicios funerarios y religiosos) e incluso la aculturación religiosa mediante la construcción de templos en los que se adora a divinidades foráneas (en el caso de La Muela, como en el Carambolo, posiblemente a Astarte) (Blázquez, 1986, a. 59-60).

Sin embargo una visión más detenida de la documentación arqueológica, indica por un lado, que el impacto de la colonización semita en el interior, se materializa en la existencia de un comercio de objetos de excepcional valor y uso restringido, relacionados frecuentemente con el mundo funerario y ritual, y en la adopción de técnicas constructivas y estilos arquitectónicos sólo válidos para edificios relacionados con las élites sociales: mausoleos, santuarios, y posiblemente viviendas de prestigio (Blázquez, 1982, 426).

La penetración hacia en el interior de todas estas aporraciones tartesias y fenicias se producirá hacia la segunda mitad del siglo VII a.C. $y$, sobre todo a partir del siglo VI a.C. (Aubet, 1977-78, 94) como consecuencia del crecimiento económico que el comercio de los metales genera en toda la zona. Tanto el control de los recursos mineros como el de las rutas de distribución y los excedentes agropecuarios estarán en manos indígenas (Aubet, 1984, 446; González Wagner, 1983, 13; Ibíd, 1986, 136), -en pocas manos-, lo que supondrá el enriquecimiento de este grupo y la adquisición de toda una serie de productos exóticos que contribuyen a distanciarlo aún más del resto de la población, y, en este sentido, al mantenimiento de este sistema a través del control de los recursos (Aubet, 1977-78, 447-48).

La situación concreta de Cástulo ha sido bien expuesta recientemente por García-Gelabert (1987) quien destaca el proceso socio-político de la ciudad oretana como una evolución desde una sociedad inicialmente igualitaria hacia una sociedad de jefatura, dinamizada por el comercio del metal y con base en el sistema de intercambios $(1987,29)$. El control de las rutas comerciales y de los excedentes hacen del sector privilegiado el principal beneficiario del sistema frente a una gran parte de la población que se encontratía en situación de servidumbre comunitaria. Algunas constantes de este tipo de sociedad son el que se origine un mayor desarrollo urbano, donde resida el sector privilegiado, ante las necesidades del mantenimiento del aparato cultural y militar, y para la conservación y protección del excedente, y que sea este sector el que se apropie de este excedente (Mangas, 1977, 153).

Sin embargo, este crecimiento económico no es consecuencia del desarrollo local, sino el resultado de la ingerencia de "grupos humanos portadotes de la técnica metalúrgica, procedentes de la zona onubense". Se hace hincapié en el cambio que se produce hacia una sociedad estratificada, de productores de excedentes, basada en el mantenimiento de grupos dedicados a los sectores secundatios y terciarios de la economía: albaniles, orfebres, metalúrgicos, etc, no relacionados directamente con la producción de alimentos "y cuyo papel estaría relacionado con la centralización y redistribución de excedentes comunales" (García -Gelabert, 1987, 31).

Por otro lado, la situación de Cástulo no puede ser generalizada para toda el área de la Alta Andalucía. Eñ primer lugar, porque Cástulo es el mayor y más importante centro de la zona, y, en este sentido, porquue "existen marcadas diferencias entre asentamientos cercanos geográficamente" (Nocete y otros, 1986, 192). Frente a una serie de transformaciones profundas en áreas geográficas concretas como la campina occidental giennense, contrastan otras zonas como el Valle del 


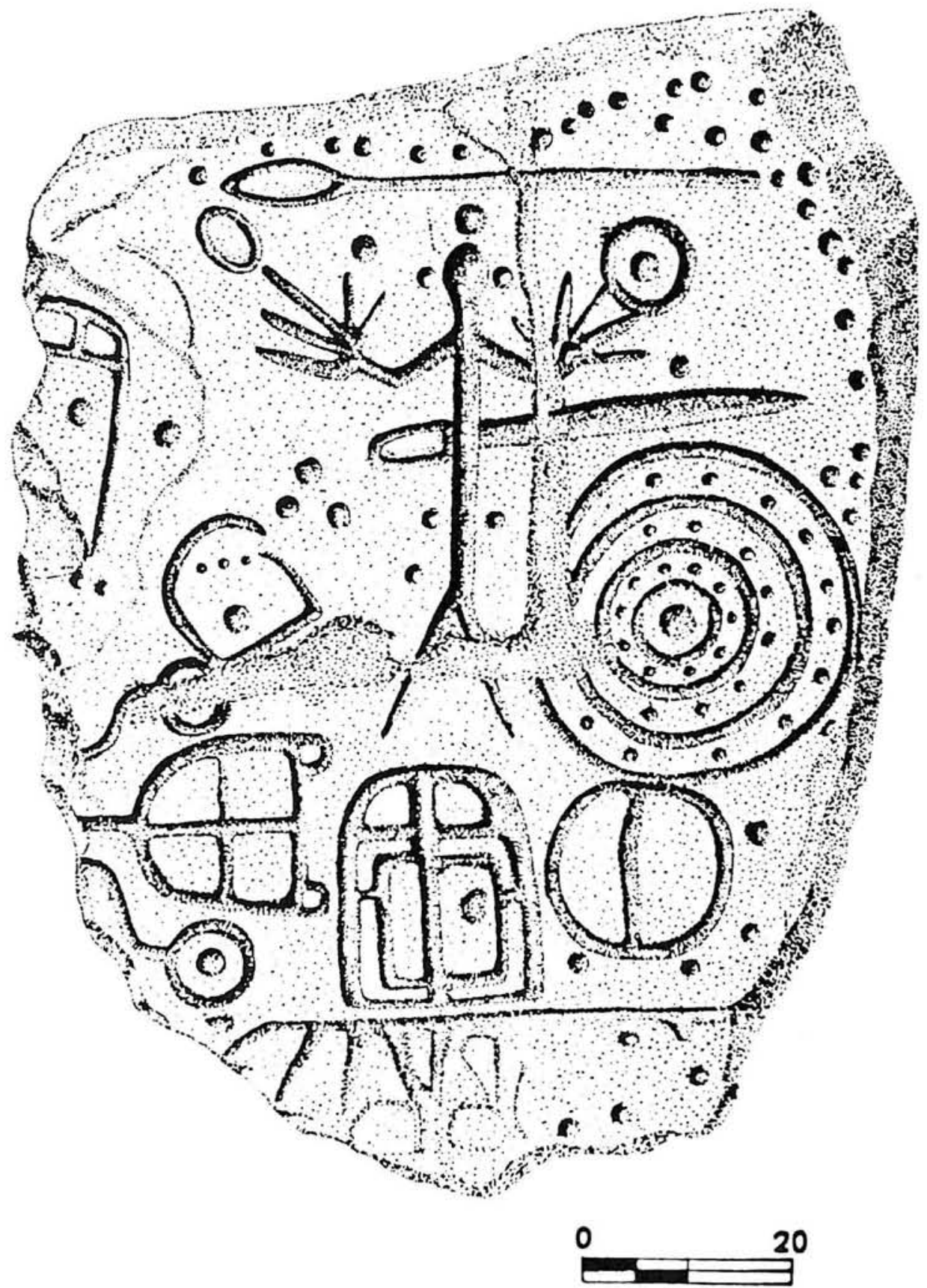

Figura No 18.- Estela de Monte Blanco, Olivenza (Badajoz). (Según P. Bueno y F. Piñón). 


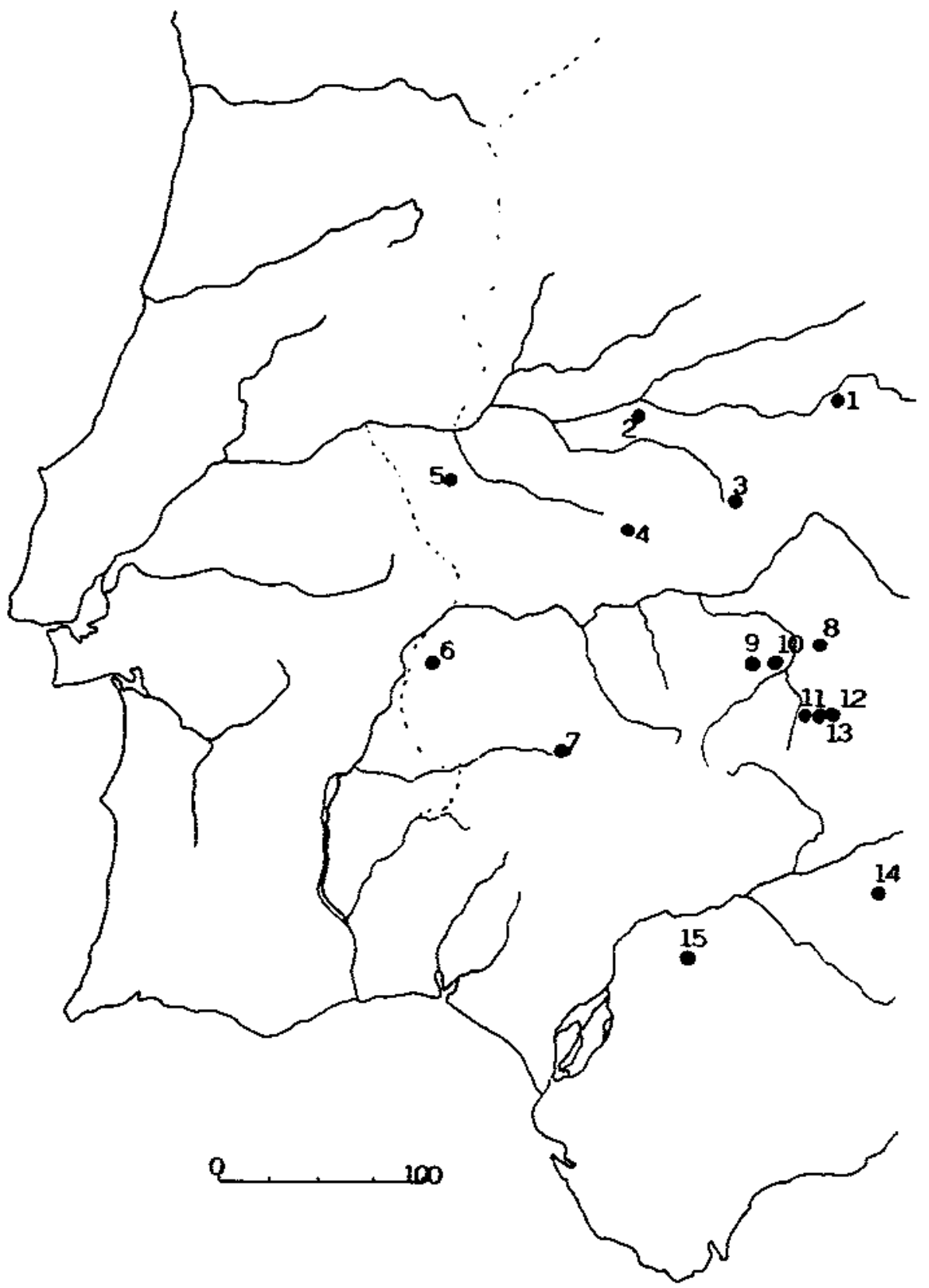

1.- Las Herencias

2.- Torrejón el Rubio I

3.- Solana de Cabañas

4.- Zarza de Montanchez

5.- Valencia de Alcántara II

6.- Monte Blanco

7.- Fuentedecantos

8.- Zarza Capilla
9.- Cabeza del Buey I

10.- Cabeza del Buey II

11.- El Viso I

12.- El Viso II

13.- El Viso IV

14.- Aregua

15.- Cuatro Casas

Figura No 19.- Distribucion de estelas con carros peninsulares. 
Guadalquivir o la Campina Oriental donde las transformaciones no son tan acusadas. Un ejemplo bien notorio puede ser el Cerro del Salto, tan sólo a unos pocos kilómetros de Cástulo, donde los cambios ocasionados por el estímulo orientalizante no se manifiestan en una transformación profunda de sus tradiciones y tecnologias. Apenas aparece cerámicas a torno, y entre el registro arqueológico de tradición ind́gena sólo se destaca el ejemplo de un peine de marfil con típica decoración orientalizante, material exótico relacionado con la élite (Nocete y otros, 1986, 193).

Otro punto que conviene resaltar, es la estrecha relación entre los sectores dirigentes de la sociedad tartésica con la economía y la religión, en una conexión muchas veces dificil de analizar y discernir. Un buen fósil director pueden ser los elementos de carros, al igual que otros materiales de la documentación arqueológica, porque aparecen tanto en necrópolis ( $\mathrm{I} a$ Joya), formando parte integrante del ajuar de un poderoso, como en santuarios (Cancho Roano), como ofrendas. Podemos relacionar también estas nociones con la importancia de la minería y su conexión inequivoca con centros rituales como La Muela en Cástulo. En La Muela I se encontró un taller de fundidores sobre el que se construyó el santuario (La Muela II) posiblemente dedicado a Astarté, divinidad oriental relacionada con las labores metalúrgicas (Blázquez, 1986, 59-62; Blázquez y Otros, 1984). Vemos pues, que estamos ante una serie de piezas intetrelacionadas en el que la correcta disposición de todos los elementos nos conducirá inexorablemente a las respuestas de los interrogantes planteados.

Por último, no se puede dejar de hacer referencia, al hablar de los carros orientalizantes, de su posible identificación con los carros representados en las estelas del Suroeste. No es este lugar para entrat en el debate sobre los origenes y cronología de estos monumentos funerarios, pero sí para dar una pequeña contribución que ayude al esclarecimiento de esta problemática. La estela de Monte Blanco (Olivenza, Badajoz) (Fig. 18), constituye una prueba ineludible del impacto orientalizante en el área tartésica (Bueno-Pińón, 1985, 43). Esstos autores la fechan en el siglo VIII a.C., y en ella se representan elementos que la telacionan directamente con los hallazgos de carros peninsulares. Se trata de un motivo circular que representa la abrazadera de un escudo de procedencia oriental, no griego, pues estos últimos cuentan con un sistema de sujeción distinto por el borde (Blázquez, 1986 b, 192). La importancia de este elemento está en la semejanza con otro objeto de caracteristica similares hallado en La Joya (Bueno-Piñón, 1985, 42) que, como sabemos, tiene entre sus ajuares al menos dos carros. De esta manera, creemos que se puede establecer una relación cronologica, todavia difícil, entre los carros representados en las estelas (Fig. 19), y los que denominamos como "orientalizantes".

En estas líneas, hemos querido dar un rápido repaso a cuestiones que precisan de análisis más profundos, pero creemos cumplido nuestros objetivos de presentar unos materiales inéditos, realizar estudios tipológicos y plantear cuestiones reabiertas al debate. 


\section{BIBLIOGRAFIA}

Almagro Basch, M., 1937: "El hallazgo de la Rla de Huelva y el final de la Edad del Bronce en el Occidente de Europa", Ampurias II: 85-143.

.. 1966: Las estelas decoradas del Suroeste, B.P.H. VIII, Madrid.

... 1979: "Los orígenes de la toreútica ibérica", Trabajos de Prehistoria 36: 173-211, Madrid.

ALMAGRO-GORBEA, M., 1977: El Bronce Final y el Periodo Orientalizante en Extremadura, B.P.H. XIV, Madrid.

... 1985: "Bronces ibéricos de Extremadura", Homenaje a Canovas Pesini 1: 71-86, Badajoz.

... 1990: "El Período Orientalizante en Extremadura", Cuadernos Emeritenses 2: 85-125, Mérida.

Aivarez Osorio, F., 1935: Bronces Ibericos o Hispanicos del M.A.N., Madrid.

ARRIBAS, A., 1967: "La necrópolis bastitana del Mirador de Rolando (Granada)", Pyrenae 3: 67-106, Barcelona.

Arribas, A. y Molina, F., 1968-69: "La necrópolis ibérica del Molino de Caldona (Finca Torrubia)", Oretania 28-33: 160-221.

AUBET, Ma2. E., 1977-78: "Algunas cuestiones en rorno al período orientalizante zartésico", Pyrenae 13-14: 81-107, Barcelona.

... 1984: "La aristocracia tartésica durante el periodo Orientalizante", Opus III: 445-68.

Barcelo, J. A., 1989: "Las estelas decoradas del Sudoeste de la Península Ibérica", Tartessos. Arqueologia Protobistórica del Bajo Guadalquivir: 189-208, Barcelona.

BendalA, M., 1977: "Notas sobre las estelas decoradas del Suroeste y los orígenes de Tartessos", Habis 8: 177-205, Sevilla.

BENDALA, M. y otros, 1979-80: "Tres nuevas estelas de guerreros en la provincia de Córdoba", Habis 1011: 381 ss.

BLAZQUEZ, J. M., 1955: "Los carros vorivos de Mérida y Almorchón", Zephyms VI: 41 ss.

... 1975: Tartessos y la Colonización Fenicia en Occidente, Salamanca.

.. 1976: "Bronces de la Mérida Prerromana", Actas del Bimilenario de Mérida : 11-74, Madrid.

... 1986 a: "La colonización fenicia en la Alta Andalucia (Oretania). S. VIII-VI a.C.", Rivista di Studi Fenici XIV, 1: 53-80, Roma.

... 1986 b: "La estela de Monte Blanco, Olivenza (Badajoz) y el origen fenicio de los escudos y de los carros representados en las losas de finales de la Edad del Bronce en la Peninsula Ibérica", Archivo Español de Arqueologia 59: 191-98, Madrid.

BiAZQuEZ, J. M. y REMESAi, J., 1975: "Hallazgos en la necrópolis oretana de Cászulo", Congreso Nacional de Arqueologia XIII: 639-58.

Blazquez, J. M. y ValienTe, J., 1982: "El poblado de La Muela y la fase orientalizante en Cátulo (Jaén)", Madrider Beitrüge 8: 407-27.

Blazquez, J. M.-Garcia-Gelabert, M.P.-LopeZ, F., 1984: "Evolución del patrón de asentamiento en Cástulo, fases iniciales", Arqueologia Espacial 4: 241-52.

BLAZQUEZ, J. M. y GARCIA-GelABERT, M.P., 1985: "Nueva campaña de excavación en la necrópolis orecana de Estacar de Robarinas, Cástulo, (Linares)”, Congreso Nacional de Arqueologia XVII: 535-49.

BonsoR, J., 1924: "Los dioses de Los Alcores", Actas y Memorias de la Sociedad Española de Antropologta, Etnografta y Prehistoria III: 175 ss.

Broncano, S. y Alfaro, Ma. DEL M., 1990: "Los caminos de ruedas de la ciudad ibérica de el Castellar de Meca (Ayora, Valencia)", Excavaciones Arqueologicas en España 162, Madrid.

Breuil, H., 1916: "Le char et le varineau dans l'ast mupestre d'Estremadure", Terra Portuguesa 15-16: 81 ss. Bueno, P. y Piñon, F., 1985: "La estela de Monte Blanco, Olivenza (Badajoz)", Homenaje a Cánovas Pesini 1: 37.44 , Badajoz. 
CABRE, J., 1924: "La rueda en la Península Ibérica", Actas y Memorias de la Sociedad Española de Antropologia, Etnografia y Prehistoria III: 7 Iss.

.. 1925: "Arquitectura hispánica. El sepulcro de Toya", Archito Espaniol de Arte y Arqueologia I: 73ss.

CABRE, J. y MOTOS, F., 1920: La necrópolis iberica de Tútugi (Galera, provincia de Granada), J.S.E.A. Mem. 25, Madrid.

Celestino, S., 1985: "Los carros y las estelas decoradas del Suroeste", Homenaje a Cánovas Pesini 1: 45-56, Badajoz.

... 1990: "Las estelas decozadas del S.W. Peninsular", Cuadernos Emeritenses 2: 45-62, Mérida.

Celestino, S. y otros, 1989 e.p.: "Paleoetnología del área extremeña", I Congreso de Paleoetnología de la peninsula Iberica, Madrid.

Cuadrado, E., 1949: "Arreos de montar ibéricos de los exvotos de El Cigarralejo", Crónica IV C.A. del S.E. Español, Cartagena.

... 1950: Excavaciones en el Santuario Iberico de El Cigarralejo (Mula, Murcia), Informes y Memorias 21, Madrid.

... 1955: "El Carro Ibérico", Congreso Nacional de Arqueologia III: 116-35.

.. 1984: "Restos monumentales funerarios de EI Cigarralejo", Trabajos de Prehistoria 41: 251-90, Madrid.

.. 1987: La necrópolis iberica de El Cigarralejo (Mula, Murcia), B.P.H. XXIII, Madrid.

CuliCAN, W., 1971: "A Phoenician Bronze from Spain", Archivo Español de Arqueologia XLIV: 156-160, Madrid.

Chaves, F. y De LA BANDera, M.L., 1991: "Aspectos de la Urbaniscica en Andalucía Occidental en los siglos VII-VI a.C. a la luz del yacimiento de Montemolin (Marchena, Sevilla)", II Congresso Internazionale di Studi Fenici e Punici II: 691-714, Roma.

DE LA BANDERA, M². L., 1979-80: "Nuevas figuras zoomorfas del Bajo Guadalquivir", Habis 10-11: 391-400.

FernandeZ Jurado, J., 1987: "Tejada La Vicja: Una Ciudad Protohistórica", Huelva Argueológica IX, 2 vol., Huelva.

Fernandez Miranda, M. y Olmos, R., 1986: Las ruedas de Toya y el origen del carro en la Peninsula lberica, Madrid.

Fernandez OXEA, J. R., 1950: "Lápidas sepulczales de la edad del Bronce en Extremadura", Archivo Español de Argueologia : 293-318.

FERRER, J., 1977: "La necrópolis megalítica de Fonelas (Granada). El sepulcro Domingo 1 y sus niveles de enterramiento", Cuademos de Prehistoria de la Universidad de Granada II: 173-211.

Fletcher, D., 1965: La Necrópolis de La Salivella, Trabajos varios del S.I.P. 32, Valencia.

FORRER, R., 1932: "Les chars cultuels préhistoriques et leur survivances aux époques historiques", Préhistoire I: 19-123.

GarCia-Gelabert, M. P., 1987: "Evolución sociopolitica de Cástulo: sociedad de jefatura", Lucentum Vl: 29-41, Alicante.

GarCIA y Bellido, A., 1970: "Algunas novedades sobre la arqueología púnico-tartessia", Archivo Español de Argueologia XLIII: 9-43, Madrid.

GaRRiDO, J.P. y ORTA, E., 1978: "Excavaciones en la slecrópolis de La Joya, Huelva. II", Excavaciones Arqueologicas en España 96, Madrid.

Gonzalez Navarrete, J. A., 1987: Escultura Ibérica de Cerrillo Blanco. Porcuna, Jaén, Jaén.

GonZalez Prats, A., 1983: Estudio Arqueologico del Poblamiento Antiguo de la Sierra de Crevillente (Alicante), Anejo I de la Revista Lucenturn, Alicante.

Gonzalez Prats, A. y PINA, J.A., 1983: "Análisis de las pastas cerámicas de vasos hechos a torno de la Fase Orientalizante de Peńa Negra (675-550/35 a.C.)", Lucentum II: 115-46, Alicante. 
GONZALEZ WAGNER, E. C., 1983: "Aproximación al proceso histórico de Tartessos", Archivo Español de Arqueologia 56: 3-36.

... 1986: "Notas en torno a la aculturación de Tartessos", Gerión IV: 129-60.

LLOBREGAT, E., 1972: Contestania Iberica, Valencia.

MAiUQueR, J., 1954: El yacimiento hallstático de Cortes de Navarta. Estudio critico I, Pamplona.

.. 1958: El yacimiento hallstático de Cortes de Navarra. Estudio crítico II, Pamplona.

.. 1981: El Santuario Protohistórico de Zalamea de La Serena, Badajoz 1.978-1.981, Barcelona.

.. 1983: El Santuario Protohistorico de Zalamea de la Serena, Badajoz, II, 1.981-1.982, Barcelona.

MaluQuer, J. y otros, 1986: El Santuatio Protohistórico de Zalamea de la Serena III, 1983-1986, Barcelona.

MANCEBO, J. y FERRER, E., 1988-89: "Aproximación a la problemática de las puncas de flecha en el período Orientalizante. El yacimiento de Pancorvo (Montellano, Sevilla)", ZephynusXLI-XLII: 315-330, Salamanca. ... 1991 e.p.: "El escarabeo de Pancorvo, Sevilla", Spal 1.

Mangas, J., 1977: "Servidumbre comunitaria en la Bética Prerromana", Memorias de Historia Antigua I: 151-61.

Martinez, C. y Botelia, M. C., 1980: El Peñón de la Reina. Alboloduy, Almeria, Excavaciones Arqueologicas en España 112, Madrid.

Muzzolini, A., 1987: "Les chars des stèles du Sud-Ouest de la Péninsule Ibérique, les chars des gravures rupestres du Maroc et la datation des chars Sahariens", Congreso Internacional: El Estrecho de Gibraltar I: 361-87, Ceuta.

Nocete, F.-Crespo, J. M.-ZafrA, N., 1986: "Cerro del Salto. Historia de una periferia", Cuadernos de Prehistoria de la Universidad de Granada 11: 171-98.

PADRo, J., 1977: "Datos para una valoración del factor egipcio y de sta incidencia en los orígenes del proceso de iberización", Ampurias 38-40: 487-509, Barcelona.

PelílCer, M., 1989: "El Bronce Reciente y los inicios del Hierro en Andalucía Occidental", Tartessos. Arqueologia Protobistbrica del Bajo Guadalquivir: 147-87, Barcelona.

PINGel, V., 1974: "Bemerkungen zu den ritverzisten Syelen uns beginen Eisenzeit im Südwesten der Iberischen Halbinsel", Hamburger Beiträge zur Archäalogie IV.

PrEsedo, F., 1982: "La necrópolis de Baza", Excavaciones Arqueologicas en España 119, Madrid.

Roso DE LuNA, M., 1898: "Lápida sepuícral de Solana de Cabańas, en el parrido de Logrosán", Boletín de La Real Academia de La Historia XXXI, Madrid.

Rulz Delgado, M. Ma., 1989 a: Fibulas Protohistóricas en el Sur de la Peninsula Iberica, Publicaciones de la Universidad de Sevilla 112, Sevilla.

... 1989 b: "Las necrópolis tartésicas: prestigio, poder y jeratquías", Tartessos. Arqueologia Protobistbrica del Bajo Guadalguivir. 247-286, Barcelona.

SANDARS, H., 1906: Preroman bronze votive offerings from Despeñaperros in the Sierra Morena, Spain, Westminster.

SCHÓLE, W., 1969: Die Meseta-Kultures der Iberischen Halbinsel, Berlín.

Serra RAfols, J. DE C. 1948: "Carrito ibérico de bronce del Museo de Granollers", Archivo Español de arqueologia XXI: 378-91.

SiRET, L., 1906: Villaricos y Herrerias. Antigüedades punicas, romanas, visigbticas y arabes, Madrid.

STARY, P., 1989: "Eisenzeitliche Wagengzäber auf der Iberischen Halbinsel", Madrider Mitteilungen 30: 151-83.

Storch de Gracia y AsenSio, J. J., 1989: La Fibula en la Hispania Antigua: Las Fíbulas Protobistóricas del Suroeste Peninsular, Universidad Complutense de Madrid 39/89, Madrid. 
VArelA, M. y Pinho, J., 1976-77: “As estelas decoradas da heredade de Pomar (Ervidel-Beja). Estudo comparado", Setúbal Arqueologica II-III: 281 -344.

... 1977: "Las estelas decoradas do Pomar (Berja, Portugal). Estudio comparado", Trabajos de Prebistoria 34, Madrid. 